medRxiv preprint doi: https://doi.org/10.1101/2021.05.10.21256880; this version posted May 11, 2021. The copyright holder for this preprint (which was not certified by peer review) is the author/funder, who has granted medRxiv a license to display the preprint in perpetuity.

It is made available under a CC-BY-NC 4.0 International license .

Characterization of direct and/or indirect genetic associations for multiple traits in longitudinal studies of disease progression

Myriam Brossard $^{1 *}$, Andrew D. Paterson ${ }^{2,3}$, Osvaldo Espin-Garcia ${ }^{3,4}$, Radu V. Craiu ${ }^{5}$, Shelley B. 4 Bull $1,3,{ }^{*}$

$5{ }^{1}$ Lunenfeld-Tanenbaum Research Institute, Sinai Health System, Toronto, ON, Canada;

${ }^{2}$ Program in Genetics and Genome Biology, Hospital for Sick Children Research Institute, Toronto, ON, Canada;

${ }^{3}$ Division of Biostatistics, Dalla Lana School of Public Health, University of Toronto, Toronto, ON, 9 Canada;

$10{ }^{4}$ Department of Biostatistics, Princess Margaret Cancer Centre, Toronto, ON, Canada;

11 5epartment of Statistical Sciences, University of Toronto, Toronto, ON, Canada.

Running title (40/40 characters): Joint models for multiple trait genetics.

\title{
Abstract (239/250)
}

When quantitative longitudinal traits are risk factors for disease progression, endogenous, and/or subject to random errors, joint model specification of multiple time-to-event and multiple longitudinal traits can effectively identify direct and/or indirect genetic association of single nucleotide polymorphisms (SNPs) with time-to-event traits. Here, we present a joint model that integrates: i) a linear mixed model describing the trajectory of each longitudinal trait as a function of time, SNP effects and subject-specific random effects, and ii) a frailty Cox survival model that depends on SNPs, longitudinal trajectory effects, and a subject-specific frailty term accounting for unexplained dependency between time-to-event traits. Inference is based on a two-stage approach with bootstrap joint covariance estimation. We develop a hypothesis testing procedure to identify direct and/or indirect SNP association with each time-to-event trait. Motivated by complex genetic architecture of type 1 diabetes complications (T1DC) observed in the Diabetes Control and Complications Trial (DCCT), we show by realistic simulation study that joint modelling of two time-to-T1DC (retinopathy, nephropathy) and two longitudinal risk factors (HbA1c, systolic blood pressure) reduces bias and improves identification of direct and/or indirect SNP associations, compared to alternative methods ignoring measurement errors in intermediate risk factors. Through analysis of DCCT, we identify two SNPs with indirect associations with multiple time-to-T1DC traits and obtain similar conclusions using alternative formulations of timedependent HbA1c effects on T1DC. In total, joint analysis of multiple longitudinal and multiple time-to-event traits provides insight into aetiology of complex traits.

Key words: joint models; longitudinal study; direct and/or indirect genetic association; pleiotropy; complex genetic architecture; multiple-trait analysis; measurement error; patient's trajectory; mixed model; frailty model.

${ }^{*}$ Corresponding authors: Lunenfeld-Tanenbaum Research Institute, 60 Murray Street, Box \#18, M5T 3L9, Toronto, ON, Canada. E-mails: bull@lunenfeld.ca, brossard@lunenfeld.ca. 
medRxiv preprint doi: https://doi.org/10.1101/2021.05.10.21256880; this version posted May 11, 2021. The copyright holder for this preprint (which was not certified by peer review) is the author/funder, who has granted medRxiv a license to display the preprint in perpetuity. It is made available under a CC-BY-NC 4.0 International license .

\section{Introduction}

Despite their known ability to improve inference in clinical and epidemiological studies, particularly in the presence of informative censoring/dropout or when longitudinal traits are measured with error $^{1-3}$, joint models for longitudinal and time-to-event outcomes have received limited attention in genetic association studies. Genome-wide association studies (GWAS) of intermediate quantitative traits (QTs) typically require follow-up studies to identify whether SNP associations detected with each of the QT(s), analyzed separately, also affect related outcomes through direct and/or indirect effects induced by those traits. Such intermediate traits may include established risk factors for related clinical outcomes and be measured with errors (e.g. biological variation). By accounting for QT measurement error and dependencies among traits, joint models can improve accuracy and efficiency of effect estimation, as well as detection of SNP associations.

The so-called shared-random-effects joint model ${ }^{4,5}$ consists of a sub-model for a single longitudinal trait and a sub-model for a single right-censored time-to-event trait. The longitudinal sub-model describes the QT as an underlying smoothed trajectory that depends on fixed effects of time and baseline covariates, as well as subject-specific random effects. The joint model association structure is induced via the functional dependence between the hazard of an event at any time $t$ and the longitudinal trait trajectory ${ }^{6,7}$. This relationship can be based on prior biological knowledge of the link between that longitudinal and time-to-event traits. As elucidated by lbrahim et $a l^{\prime}$, this class of joint models lends itself to interpretations of direct/indirect effects because the relationship between a baseline covariate, such as a SNP genotype, and each of the longitudinal and time-to-event traits, as well as the relationship between the longitudinal and time-to-event traits can be specified via model parameters corresponding to direct, indirect and overall effects. Extensions of joint models for multiple longitudinal and/or multiple time-to-event traits can further improve inference by borrowing information among related traits. Extensions of joint models have been reviewed for multiple longitudinal traits ${ }^{6,7}$ or multiple time-to-event traits ${ }^{8}$. A few extensions for both multiple longitudinal and multiple time-to-event traits have been developed ${ }^{9-11}$, among others), but these models are often formulated for a specific study question, and thus can lack generalizability. Such extensions raise computational challenges for maximisation of the likelihood under the multivariate random effect's distribution. Two-stage approaches ${ }^{12-15}$ for joint model fitting appear more computationally efficient and lends itself to more flexible model formulation but inference can be mis-calibrated because parameter estimates and predictions from Stage 1 are obtained from the longitudinal model without consideration of the time-to-event outcome, and the uncertainty in Stage 1 estimates is ignored during Stage 2 estimation, a problem known as propagation of errors ${ }^{16}$.

Motivated by the complex genetic architecture of long-term type 1 diabetes complications (T1DC), we propose joint-model extension to evaluate genetic associations with multiple time-to-event traits and multiple longitudinal risk factors. Risk of development of T1DC, including diabetic retinopathy (DR) and diabetic nephropathy (DN), is hypothesized to result from multiple genetic factors with potential direct and/or indirect effects via multiple - shared and/or specific - risk factors ${ }^{17}$. In addition to genetic factors, hyperglycemia (measured by Hemoglobin A1c, referred as $\mathrm{HbA1c}$ ) represents the major QT risk factor for T1DC. Other measured longitudinal traits, that can also be influenced by genetic factors, have postulated associations with T1DC, for example, 
medRxiv preprint doi: https://doi.org/10.1101/2021.05.10.21256880; this version posted May 11, 2021. The copyright holder for this preprint (which was not certified by peer review) is the author/funder, who has granted medRxiv a license to display the preprint in perpetuity. It is made available under a CC-BY-NC 4.0 International license .

association of systolic blood pressure (SBP) with DN. Because conventional analysis methods in GWAS ignores dependency between related traits, SNPs can appear associated with multiple traits (including SNPs with direct and/or indirect effects induced by intermediate QT(s) measured or unmeasured). Accurately distinguishing between direct and/or indirect associations is crucial to elucidate the biological pathways through which genetic factors operate into the etiology of those complex traits, like in our motivating example of the T1DC genetic architecture. A naïve approach to disentangle direct from indirect associations can be achieved by including the intermediate QT as a time-dependent covariate in a Cox Proportional Hazard (PH) model. However, measurement errors in intermediate QT(s), presence of informative censoring in longitudinal trait, unmeasured shared risk factors between longitudinal/time-to-event traits can challenge accurate classification of direct and/or indirect SNP associations.

The major contribution of our work is a general formulation for the joint analysis of multiple timeto-event traits and multiple longitudinal QT risk factors in genetic association studies. We develop inference methods for statistical genetic analysis based on joint model parameters estimation, including a hypothesis testing procedure to classify direct and/or indirect SNP associations with each time-to-event trait. A second contribution of the paper is the implementation of a datainformed simulation algorithm to generate multiple causal SNPs with various direct effects on simulated time-to-event traits and/or indirect effects via observed (measured) longitudinal QTs in the Diabetes Control and Complications Trial (DCCT) study ${ }^{18,19}$ and unobserved (simulated) longitudinal QTs. This algorithm also provides a general approach to estimate achievable power given sample size. Our simulation results show bias reduction and improved classification of direct and/or indirect SNP associations in comparison with alternative approaches ignoring measurement errors in longitudinal QT(s). Thirdly, we apply the joint model in DCCT data and clarifies two SNPs as having indirect associations via the HbA1c longitudinal risk factor, with consistent conclusions using alternative time-dependent association structures that account for established cumulative and time-weighted effects of $\mathrm{HbA1C}$ on T1DC traits ${ }^{20,21}$. Example R codes for data simulation and for application of the proposed joint model are available on GitHub.

\section{Methods}

\section{Joint Modelling Approach}

\section{Model Formulation}

We assume that a set of $M$ SNPs are available with $K(1 \leq k \leq K)$ unordered and non-competing time-to-event traits, such as multiple disease complications, and $L(1 \leq I \leq L)$ longitudinal QT traits (i.e. intermediate risk factors) possibly measured with error (i.e. biological variation) in Nunrelated individuals indexed by $i(1 \leq i \leq N)$. For each $\operatorname{SNPm}(1 \leq m \leq M)$, with minor allele frequency (MAF) $p_{m}$, the genotypes are coded as the number of copies of the minor allele, under an additive genetic model. For each individual $i, Y_{i(l)}=\left(y_{i(l)}\left(t_{i 1}\right), \ldots y_{i(l)}\left(t_{i j}\right), \ldots, y_{i(l)}\left(t_{i n_{i(l)}}\right)\right)^{\prime}$ denotes the vector of quantitative measures collected over scheduled visits at $t_{i j}$ for $j=1, \ldots, n_{i}$ for the $t^{\text {th }}$ longitudinal trait $(1 \leq I \leq L)$ with $n_{i}$ represents the maximum number of visits recorded. Let $\left(T_{i(k)}, \delta_{i(k)}\right)$ be the vector of observed right-censored event time $T_{i(k)}$ and event indicator $\delta_{i(k)}$ for the $k^{\text {th }}$ time-to-event trait. 
medRxiv preprint doi: https://doi.org/10.1101/2021.05.10.21256880; this version posted May 11, 2021. The copyright holder for this preprint (which was not certified by peer review) is the author/funder, who has granted medRxiv a license to display the preprint in perpetuity. It is made available under a CC-BY-NC 4.0 International license .

We assume $T_{i(k)}=\min \left(T_{i(k)}^{*}, C_{i}\right)$, where $T_{i(k)}^{*}$ is the latent (uncensored) time-to-event $k$ and $C_{i}$ is the censoring time (e.g. administrative censoring). We define $\delta_{i(k)}=I\left(T_{i(k)}^{*} \leq C_{i}\right)$, with $\delta_{i(k)}=1$ if the event occurs during the observation period $\left(T_{i(k)}^{*} \leq C_{i}\right)$ and $\delta_{i(k)}=0$ otherwise.

To characterize the genetic architecture of a system of multiple time-to-events and multiple longitudinal risk factors, we formulate a shared-random-effects joint model, as specified in Figure 1, combining: (i) longitudinal and (ii) time-to-event sub-models connected by (iii) specified time-dependent association structures.

[Insertion of Figure 1]

\section{(i) Longitudinal sub-model}

The longitudinal sub-model is specified by a multivariate mixed model for the $L$ longitudinal QTs (or risk factors), based on the multivariate extension of the Laird and Ware linear mixed model ${ }^{22}$. It describes each vector of observed longitudinal QT measures $Y_{i(l)}\left(t_{i j}\right)$ as noisy observations of a true and unobserved smoothed subject-specific longitudinal trajectory, $Y_{i(l)}^{*}\left(t_{i j}\right)$, with noise terms $\varepsilon_{i j(l)} \sim N\left(0, \sigma_{(l)}^{2}\right)$. Each smooth trajectory describes subject-specific evolution and depends on time, SNP effect, individual-level random effects $b_{i(l)}$ and can also include effects of other baseline covariates, for example confounding factors or ancestry-related principal components. To simplify the presentation, we assume a linear trajectory, but the longitudinal sub-models can be adapted for nonlinear trajectories using, for example, higher order polynomials or splines ${ }^{23}$.

\section{Multivariate mixed model}

$Y_{i(l)}\left(t_{i j}\right)=Y_{i(l)}^{*}\left(t_{i j}\right)+\varepsilon_{i j(l)}$

$Y_{i(l)}^{*}\left(t_{i j}\right)=\beta_{0(l)}+b_{i 0(l)}+\left(\beta_{1(l)}+b_{i 1(l)}\right) t_{i j}+\beta_{g(l)} S N P_{i}+\beta_{h(l)} H_{i(l)}$

\section{(smooth trajectory, Equation 2)}

Where:

- $\quad \beta_{0(l)}, \beta_{1(l)}, \beta_{g(l)}$ and $\beta_{h(l)}$ denote, respectively, the fixed intercept, and baseline effects of time, SNP and other covariate(s) on each longitudinal trait $l$.

- $b_{i}=\left(\left(b_{i 0(l)}, b_{i 1(l)}\right)^{\prime}, \ldots,\left(b_{i 0(L)}, b_{i 1(L)}\right)^{\prime}\right)^{\prime}$ is the $2 \times L$ vector of random effects with $b_{i} \sim N_{2 L}(0, D)$.

- $\quad D=\left(\begin{array}{ccc}D_{1,1} & \cdots & D_{1, \mathrm{~L}} \\ \vdots & \ddots & \vdots \\ D_{L, 1} & \cdots & D_{L, L}\end{array}\right)$ denotes the overall variance-covariance matrix for random effects, accounting for serial dependencies within longitudinal traits $\left(D_{l, l}\right.$, unstructured) and crossdependencies between longitudinal traits $\left(D_{l, m}\right.$ for two traits $\left.l \neq m\right)$. 
medRxiv preprint doi: https://doi.org/10.1101/2021.05.10.21256880; this version posted May 11, 2021. The copyright holder for this preprint (which was not certified by peer review) is the author/funder, who has granted medRxiv a license to display the preprint in perpetuity. It is made available under a CC-BY-NC 4.0 International license .

- $\varepsilon_{i(l)}=\left(\varepsilon_{i 1(l)}, \ldots, \varepsilon_{i j(l)}, \ldots, \varepsilon_{i n_{i}(l)}\right)^{\prime}$ is the vector of error terms where $\varepsilon_{i j(l)} \sim N\left(0, \sigma_{(l)}^{2}\right)$ is assumed independent and identically distributed.

- $\sigma_{(l)}^{2}$ is the residual variance of the QT $l$. We further assume that $\varepsilon_{i j(l)}$ and $b_{i(l)}$ are independent ${ }^{22}$.

\section{(ii) Time-to-event sub-model}

The time-to-event sub-model is specified by a Proportional Hazards (PH) mixed effects model (also known as frailty $\mathrm{PH}$ model) where the hazard function of each time-to-event trait $k$ depends on the SNP effect adjusted for a function of the subject's longitudinal trajectories $W_{i(k)}(t)$. We introduce a subject-specific random effect (frailty term, $u_{i}$ ) to capture unexplained dependencies (e.g. due to unmeasured shared factors) among the $K$ time-to-event traits. Given the common frailty term $u_{i}$, the $K$ time-to-event traits are assumed independent ${ }^{24}$.

Proportional Hazards mixed effects sub-model

$\lambda_{i(k)}(t)=\lambda_{0(k)}(t) \times \exp \left\{\gamma_{g(k)} S N P_{i}+W_{i(k)}(t)+\gamma_{v(k)} V_{i(k)}+u_{i}\right\} \quad$ (Equation 3)

Where:

- $\lambda_{0(k)}(t)$ is a (parametric or non-parametric) baseline hazard function for the time-to-event trait $k$.

- $\quad \gamma_{g(k)}$ denotes the SNP effect on the time-to-event $k$ adjusted for the indirect SNP effects via longitudinal QT(s), taken into account by $W_{i(k)}(t)$.

- $\quad \gamma_{v(k)}$ is the effect of the baseline covariate vector(s). Those covariates can be shared or trait-specific covariates. They can also be time-dependent covariates for all or a subset of the $K$ time-to-event traits (in this case, $V_{i(k)}=V_{i(k)}(t)$ ).

- $u_{i}$ and $b_{i}$, random effects from the time-to-event and longitudinal sub-models respectively, are assumed independent. We assume $u_{i} \sim \Gamma(a, b)$, with $a, b>0$.

\section{(iii) Time-dependent association structures}

The time-dependent association structures, $W_{i(k)}(t)$, that connect the longitudinal and time-toevent sub-models (Figure 1), account for the specific temporal relationships between each set of $L_{k}\left(1 \leq L_{k} \leq L\right)$ associated QT(s) and each time-to-event trait $k$.

$W_{i(k)}(t)=\sum_{l=1}^{L_{k}} \alpha_{l(k)} f_{l(k)}\left(Y_{i(l)}^{*}(t)\right)$

(Equation 4)

\section{Where:}

- $1 \leq L_{k} \leq L$ is the set of longitudinal risk factors of the time-to-event trait $k$.

- $f_{l(k)}\left(Y_{i(l)}^{*}(t)\right)$ denotes the functional form of the exposure effect on time-to-event trait $k$ corresponding to the 1 -th longitudinal risk. In the case of a contemporaneous parametrization, the hazard of an event $k$ at a time $t$ depends on the longitudinal trait value 
medRxiv preprint doi: https://doi.org/10.1101/2021.05.10.21256880; this version posted May 11, 2021. The copyright holder for this preprint (which was not certified by peer review) is the author/funder, who has granted medRxiv a license to display the preprint in perpetuity. It is made available under a CC-BY-NC 4.0 International license .

at the same time $t$ (i.e. $\left.f_{l(k)}\left(Y_{i(l)}^{*}(t)\right)=Y_{i(l)}^{*}(t)\right)$. Other parametrizations have been described in the literature $\mathrm{e}^{6,7,25}$.

- $\alpha_{l(k)}$ denotes the association parameter of the function of the smooth longitudinal trajectory $Y_{\mathrm{i}(l)}^{*}(t)$ with the time-to-event $k$.

- $Y_{\mathrm{i}(l)}^{*}(t)=\left\{Y_{\mathrm{i}(l)}^{*}(s)\right.$, with $\left.0 \leq s \leq t, 1 \leq l \leq L\right\}$ denotes the history of the underlying longitudinal trajectory for trait / up to time $t$.

\section{Interpretation}

When the joint model is correctly specified, the parameters accurately represent multiple relationships between each SNP and the correlated traits. Note that $\beta_{g(l)}$ is the SNP effect on the longitudinal risk factor $I, \gamma_{g(k)}$ is the direct SNP effect on the time-to-event trait $k$ via other mechanisms than the indirect SNP association induced by the observed longitudinal risk factors. In this context, $\theta_{k(l)}=\mu_{g(k, l)}+\gamma_{g(k)}$ is interpreted as the overall SNP effect on the time-to-event trait $k$, where $\mu_{g(k, l)}=\alpha_{l(k)} \beta_{g(l)}$ represents the indirect ${ }^{1}$ SNP effect on the time-to-event trait $k$ via the longitudinal QT I.

Under the proposed joint model formulation, when a longitudinal risk factor $/$ is associated with a time-to-event trait $k\left(\alpha_{l(k)} \neq 0\right)$, a SNP that has an effect on the longitudinal QT risk factor $I\left(\beta_{g(l)} \neq\right.$ $0)$, but no effect on the time-to-event trait $k\left(\gamma_{g(k)}=0\right)$, is interpreted as having an indirect SNP association and its overall effect is equal to its indirect effect $\left(\theta_{k(l)}=\mu_{g(k, l)}\right.$, with $\mu_{g(k, l)}=$ $\left.\alpha_{l(k)} \beta_{g(l)}\right)$. A SNP with an effect on the time-to-event trait $k\left(\gamma_{g(k)} \neq 0\right)$, but no effect on the longitudinal QT I $\left(\beta_{g(l)}=0\right)$, is interpreted as having a direct SNP association and its overall effect is equal to its direct effect $\left(\theta_{k(l)}=\gamma_{g(k)}\right)$. A SNP with an effect on the longitudinal risk factor $l\left(\beta_{g(l)} \neq 0\right)$ and an effect on the time-to-event trait $k\left(\gamma_{g(k)} \neq 0\right)$ is interpreted as having both direct and indirect SNP associations via distinct genetic pathways. In this case, its overall effect is an aggregation of both direct and indirect effects $\left(\theta_{k(l)}=\mu_{g(k, l)}+\gamma_{g(k)}\right.$, with $\left.\mu_{g(k, l)}=\alpha_{l(k)} \beta_{g(l)}\right)$. It is obvious that when an associated longitudinal risk factor is omitted from a time-to-event model, as occurs in separate analyses of longitudinal and time-to-event traits, the marginal SNP effect on the time-to-event trait will reflect partially the overall SNP effect $\theta_{k(l)}$. This is particularly the case in GWAS when intermediate risk factors are ignored in the analysis models.

\section{Effect estimation and test statistic construction}

To mitigate the computational complexity involved in the maximization of the joint likelihood and allow more flexibility in the model formulated, we estimate the parameters using a two-stage approach (see Appendix). We work within the framework defined by Tsiatis and Davidian ${ }^{26,27}$ which guarantees that our estimators are consistent and asymptotically normal. Specifically, in Stage 1 we fit the multivariate mixed model (Equation 1) using the mvlme() function from the $\mathrm{R}$ package JoineRML ${ }^{28}$ to estimate the parameters of the longitudinal trajectories of the risk factors (Equation 2), and obtain fitted values of the smoothed trajectories. In Stage 2, we fit a Cox PH frailty time-to-event model (Equation 3) adjusting for functions of the smoothed trajectories as 
medRxiv preprint doi: https://doi.org/10.1101/2021.05.10.21256880; this version posted May 11, 2021. The copyright holder for this preprint (which was not certified by peer review) is the author/funder, who has granted medRxiv a license to display the preprint in perpetuity. It is made available under a CC-BY-NC 4.0 International license .

time-dependent covariates using the $\operatorname{coxph}()$ function from the $\mathrm{R}$ survival ${ }^{29,30}$ package. We assume a Gamma distribution for the frailty term $\left(u_{i}\right)$ and a separate baseline hazard function for each time-to-event trait using the strata argument in coxph(). To account for propagation of errors, due to the uncertainty in Stage 1 estimates ignored during Stage 2 parameter estimation ${ }^{16}$ and empirically estimate the joint covariance matrix of SNP and trajectories effects we apply a nonparametric bootstrap ${ }^{31}$. For each bootstrap sample $b(1 \leq b \leq B, B$ is the total number of bootstraps), we generate a new dataset by randomly sampling $N$ individuals with replacement and refitting the joint model on each new dataset $b$. We compute the empirical joint covariance matrix of the estimated parameters using the $B$ bootstrap parameter estimates. Wald statistics for each $\beta_{g(l)}$ are computed as $S_{\beta_{g(l)}}=\widehat{\beta_{g(l)}} / s e_{\beta_{g(l)}}$ using the empirical bootstrap standard errors $s e_{\beta_{g(l)}}$, and similarly for each $\gamma_{g(k)}$ as $S_{\gamma_{g(k)}}=\widehat{\gamma_{g(k)}} / s e_{\gamma_{g(k)}}$.

\section{Procedure to classify direct/indirect SNP associations}

In Table 1, we present a practical hypothesis testing procedure to classify SNPs as having direct and/or indirect association with a time-to-event trait $k$ and each associated longitudinal risk factor $I$. This procedure requires two significance thresholds, $P_{\beta_{g}}^{*}$ and $P_{\gamma_{g}}^{*}$ for $\beta_{g(l)}$ and $\gamma_{g(k)}$ respectively, to be specified prior to the analysis and adjusted for the number of SNPs tested. Depending on the research question, we can choose different values for $P_{\beta}^{*}$ and $P_{\gamma}^{*}$, or the same one $\left(P^{*}=P_{\beta_{g}}^{*}=\right.$ $P_{\gamma_{g}}^{*}$ ). The latter is applicable for instance, when we want to systematically classify direct/indirect association among a set of MSNPs, and the former when assessing which SNPs, among the ones reported to be associated with the longitudinal risk factor, have a direct effect on a time-toevent trait.

\section{[Insertion of Table 1]}

\section{Motivation: The DCCT Studies}

The DCCT randomized-controlled trial was pivotal in demonstrating that intensive insulin therapy prevents and delays progression of long-term T1DC ${ }^{18}$. Due to significant outcome differences between the intensive and conventional treatment groups at interim analysis, the DCCT trial was stopped early. At the closeout visit, patients were administratively censored and had a mean follow-up time of 6.5 years (range 3 to 9 ), $99 \%$ had completed the study, and more than $95 \%$ of all scheduled examinations were completed ${ }^{18}$. DCCT participants continued to be followed for disease progression after the trial in a long-term epidemiologic cohort study and were genotyped for GWAS in the DCCT Genetics Study. Because the goal of intensive therapy was to reduce $\mathrm{HbA1c}$ into the non-diabetic range, which produced treatment differences in $\mathrm{HbA1c}$ values, we focus on $N=667$ unrelated individuals of European descent ancestry from the Conventional treatment group. Longitudinal measurements for $\mathrm{HbA1c}$ and SBP were collected at up to 39 quarterly visits during DCCT, while DR and DN events were diagnosed at annual and semi-annual visits respectively. $\mathrm{HbA1C}$ and SBP were recorded irrespective of the occurrence of any complication event(s). Although the DCCT implemented robust quality assurance procedures to minimize potential sources of error during and after data collection ${ }^{32,33}, \mathrm{HbA} 1 \mathrm{c}$ and SBP are 
medRxiv preprint doi: https://doi.org/10.1101/2021.05.10.21256880; this version posted May 11, 2021. The copyright holder for this preprint (which was not certified by peer review) is the author/funder, who has granted medRxiv a license to display the preprint in perpetuity. It is made available under a CC-BY-NC 4.0 International license .

subject to measurement error (e.g. individual variability). The first GWAS to analyze the DCCT study phenotypes ${ }^{19}$ identified two SNPs associated with cumulative $\mathrm{HbA1C}$ at genome-wide significance in the Conventional treatment arm, namely rs10810632 (in BNC2, 9p22.2) and rs1358030 (near SORCS1, 10q25.1), and reported consistent associations with secondary outcomes of time-to-DR and/or time-to-DN. Subsequent association studies also reported suggestive evidence for pleiotropy between $\mathrm{DR}$ and $\mathrm{DN}^{34}$. To preserve the inherent withinindividual variability, we designed simulation study evaluations of the joint modelling approach that generates event times from HbA1c and SBP measurements in the DCCT Study data.

\section{Simulation study}

\section{Design of the DCCT-data-based simulation study}

To assess the performances of the methods, we simulate the data under a genetic causal scenario that imitates the complex genetic architecture of T1DC (Figure 2). The genetic association model involves $N=667$ DCCT subjects with $K=2$ non-independent simulated time-toT1DC traits (DR, DN) that depend on $M=5$ causal SNPs with direct effects on each time-to-T1DC and/or indirect effects via $L=3$ longitudinal QTs: two as measured in DCCT (HbA1c, SBP) and one other simulated $(U)$ to induce some unexplained shared dependency between the T1DC traits. We also introduce an effect of sex on SBP, and effects of T1D duration (at baseline) on both T1DC traits, as observed in the original DCCT data.

\section{[Insertion of Figure 2]}

\section{Algorithm for realistic data generation under a complex genetic architecture}

To generate such a data structure that combines observed and simulated traits, we formulate a data generating model including: (i) $L=3$ linear mixed models linking each of the SNPs with an indirect effect to each longitudinal risk factor, and (ii) $K=2$ non-independent parametric time-toevent models depending on SNPs with direct effects and on functions of the longitudinal QT trajectories. For each DCCT individual $i$ with observed $\operatorname{HbA1c}\left(Y_{i(1)}\right)$, SBP $\left(Y_{i(2)}\right)$, visit times $\left(t_{i}\right)$ vectors at $n_{i}$ time points, and covariates $\left(H_{i(l)}, V_{i(k)}\right)$, we simulate longitudinal trait vector $U_{i}$, timeto-event traits and genetic data at $M$ causal SNPs as illustrated in Figure 3 and detailed in Supplementary Information SI-1. All SNPs are simulated under Hardy-Weinberg and linkage equilibrium assumptions. Particularly, SNPs with indirect effects are simulated from the observed (SNP1, SNP5) or simulated (SNP3) longitudinal QTs, while SNPs with direct effects (SNP2, SNP4) on time-to-T1DC traits are simulated independently of the longitudinal QTs and are included in the specified hazard function used to simulate each time-to-event trait $k$ (Figure 3).

\section{[Insertion of Figure 3]}

For each SNPm, we specify MAF $\left(p_{m}\right)$ and the SNP effects $\left(\beta_{g(l)}, \gamma_{g(k)}\right)$, as well as the other parameter values according to the DCCT Genetics Study and the T1DC literature (Table 2, 
medRxiv preprint doi: https://doi.org/10.1101/2021.05.10.21256880; this version posted May 11, 2021. The copyright holder for this preprint (which was not certified by peer review) is the author/funder, who has granted medRxiv a license to display the preprint in perpetuity. It is made available under a CC-BY-NC 4.0 International license .

Tables S1). We assume contemporaneous association structures for HbA1c and SBP effects on simulated time-to-T1DC traits. We simulate each time-to-event trait $k$ under a Weibull model, with shape and scale parameters specified to generate $\sim 54 \%$ DR events and $\sim 25 \%$ DN events in each of the $R=1000$ replicated datasets generated under the causal scenario from Figure 2. Under the global null genetic scenario, where none of the SNPs is associated with any traits, we simulate $M$ SNPs independently of the traits with the same MAF as for the causal SNPs.

Scenarios for DCCT-based complex genetic architecture

Overall, the simulated complex genetic architecture covers multiple types of SNP-trait associations (Figure 2 and Table 2): direct association with each T1DC trait (SNP2, SNP4), indirect associations with both T1DC traits via measured (SNP1) and unmeasured (SNP3) longitudinal QTs; and direct and indirect associations via a measured longitudinal QT (SNP5); all longitudinal risk factors are subject to measurement error. Except for SNP3, all other SNP scenarios represent GWAS discovery SNPs detectable by separate GWAS of a longitudinal risk factor (SNP1, SNP5) or a time-to-event trait (SNP2, SNP4, SNP5).

\section{[Insertion of Table 2]}

SNP1, SNP3 and SNP5 have indirect effects on T1DC traits, such that their associations with the T1DC traits are detectable with the marginal Cox PH time-to-event models (Tables 2 and S2). SNP1 corresponds roughly to rs 10810632 and rs 1358030 reported in the motivating DCCT GWAS of $\mathrm{HbA1c^{19 }}$, while SNP5 represents a top hit detected by each GWAS (longitudinal and time-to-event traits), analyzed separately. Because of their association with longitudinal and timeto-event traits, SNP1 and SNP5 associations with time-to-event outcomes are conventionally investigated using the Cox $\mathrm{PH}$ model adjusting for the observed longitudinal trait as a timedependent risk factor to determine if SNP association with the time-to-event trait is fully (or partially) explained via the associated longitudinal QT(s).

\section{Analysis of the simulated data}

For the analysis of each SNP, done separately, we compare four analysis models on the simulated data:

- JM-cmp: a completely specified joint model that includes all other non-SNP variables used for the data simulation.

- JM-mis: includes the same variables as JM-cmp, except $U$, the unobserved longitudinal QT.

- JM-sep $(k)$ : includes the same variables as JM-mis but is fitted separately for the two timeto-event traits. JM-sep $(k)$ does not account for the shared dependency between the timeto-event traits.

- CM-obs: a Cox PH frailty model that includes the same variables as JM-mis, but adjusts for the observed longitudinal QT values as time-dependent covariates. 
medRxiv preprint doi: https://doi.org/10.1101/2021.05.10.21256880; this version posted May 11, 2021. The copyright holder for this preprint (which was not certified by peer review) is the author/funder, who has granted medRxiv a license to display the preprint in perpetuity. It is made available under a CC-BY-NC 4.0 International license .

Due to the latent nature of $U, J M-c m p$ cannot be fitted in practice because $U$ is unobserved, but we include it as a benchmark for comparison against the observable models fitted without $U$. For all these models, empirical covariance matrices are computed using 500 bootstrap iterations. We assess the performance of the hypothesis testing procedure to classify direct/indirect association for each of the 5 causal SNPs analyzed separately with each joint model (JM-cmp, JM-mis). To assess the impact of longitudinal trait measurement errors on classification of SNPs, we substitute test $P_{\gamma_{g(k)}}$ for $\gamma_{g(k)}$ estimated by the joint model by $P_{\gamma_{g(k)}}$ obtained with CM-obs. In our evaluations, we assume the level of significance $P^{*}$ such that $P^{*}=P_{\beta}^{*}=P_{\gamma}^{*}$, with $P^{*}$ varying from 0.05 to $5 \times 10^{-}$

8. Under the causal genetic scenario, we estimate for each SNP the proportion of replicates that detect the correct direct and/or indirect association simulated (correct classification rate) and the proportion of replicates where the causal SNP association is misclassified (misclassification rate). Under the global null genetic scenario, we assess the classification test for each SNP and each type of association at $P^{*}=0.05$ and $P^{*}=0.01$ to assess the type I error control of the hypothesis testing procedure for each test of direct and/or indirect association.

\section{Availability}

DCCT data are available to authorized users at https://repository.niddk.nih.gov/studies/edic/ and https://www.ncbi.nlm.nih.gov/projects/gap/cgi-bin/study.cgi?study id=phs000086.v3.p1. Example $\mathrm{R}$ codes for DCCT-data-based simulation and analysis of the simulated data are provided on GitHub (https://github.com/brossardMyriam/Joint-model-for-multiple-trait-genetics). File S1 includes the Supplementary Information; File S2 includes the Supplementary Figures and File S3 includes the Supplementary Tables.

\section{Results}

\section{Simulation results}

\section{Estimation accuracy and single-parameter tests validity}

When the longitudinal QT(s) are observed and measured with random errors, the simulation results confirm that the proposed joint model reduces the bias of the parameter estimates for all types of SNP association (Figure S1 and Tables S3-S6), even when the analysis model is not fully specified. This applies when: (i) two correlated time-to-event traits are analyzed jointly rather than separately in the joint model (JM-cmp/JM-mis compared to JM-sep(k)); (ii) a SNP has a direct effect on a time-to-event trait with a low event rate (SNP4/SNP5, JM-cmp/JM-mis compared to CM-obs); (iii) a SNP has an indirect effect via a longitudinal QT measured with errors (for example SNP5, JM-cmp/JM-mis compared to CM-obs). Particularly, for SNP5, CM-obs overestimates the direct SNP5 effect on time-to-DN due to its inability to fully account for the indirect SNP5 effect induced via SBP. Direct SNP2 and SNP4 effects on time-to-T1DC traits show overall the larger relative bias reduction using joint models versus CM-obs (Ranges with JM-mis 0.702-0.983, with JM-cmp 0.934-0.966, see Tables S4 and S6). 
medRxiv preprint doi: https://doi.org/10.1101/2021.05.10.21256880; this version posted May 11, 2021. The copyright holder for this preprint (which was not certified by peer review) is the author/funder, who has granted medRxiv a license to display the preprint in perpetuity. It is made available under a CC-BY-NC 4.0 International license .

When a SNP has an indirect effect on both T1DC traits fully explained via an unmeasured longitudinal QT (SNP3), all methods that ignore the longitudinal QT (JM-mis, JM-sep(k) or CMobs compared to JM-cmp) produce biased direct SNP3 estimates for both T1DC towards the overall SNP3 effect $\left(\theta_{k(U)}=\alpha_{U(k)} \beta_{g(U)}=0.36\right.$, Figure S1-c and S1-d, Table S5). In this scenario, the use of the frailty term in JM-mis does not reduce this bias (JM-mis vs JM-sep).

\section{Classification of direct/indirect SNP associations with time-to-event traits}

Under the global null genetic scenario of no genetic association with any of the traits, singleparameter SNP test $P$-values $P_{\beta_{g(l)}}$ and $P_{\gamma_{g(k)}}$ from the joint model do not show departure from the expected large sample distributions ( $\chi^{2}$ with 1 degree of freedom (df), see Figure S2) and the type I error of each test under the null is reasonably well controlled (Table S7). The hypothesis testing procedure applied to single-parameter SNP tests, classifies each SNP as direct or indirect association with each T1DC trait with rates close to the nominal level (Table $\mathbf{3}$ and Figure S3). However, the classification rates for test of direct and indirect SNP association test appears less than nominal (see Table 3 for SNP5 with SBP/DN traits and Figure S3 for the other SNPs with other QT/time-to-event trait pairs).

\section{[Insertion of Table 3]}

Under the causal scenario, the hypothesis testing procedure has high correct classification rates for indirect (SNP1) or direct associations (SNP2, SNP4), as shown in Figures 4-a, 4-b and S4. Conclusions are similar for JM-mis, with attenuated correct classification rates compared to JMcmp for direct SNP associations but still higher than classification rates based on CM-obs (particularly for SNP4). Compared to results based on CM-obs, the largest relative classification improvement is found for direct SNP4 association with DN (ranges: 1.18-251.9 with JM-cmp and 1.18-110.98 with JM-mis, Figure 4).

[Insertion of Figure 4]

On the other hand, SNP3 with an indirect effect via the unobserved longitudinal trait $U$, is most frequently detected incorrectly as a direct association with each T1DC trait by both JM-mis and CM-obs (Figure 4-b). SNP5, which has both direct and indirect effects on DN induced via SBP, is most frequently misclassified by $\mathrm{JM}$-cmp and $\mathrm{JM}$-mis as an indirect association at significance levels varying from $P^{*}=0.01$ to $5 \times 10^{-8}$ (Figure 4-c and 4-d). SNP5 misclassification rate even increases with $P^{*}$ decreasing to $5 \times 10^{-8}$, due to the direct SNP5 $P_{\gamma_{g(k)}}$. In comparison, the procedure based on CM-obs results most frequently correctly classify SNP5 association in more than $75 \%$ of the replicates at the same significance levels (Figures 4-c and 4-d); this is explained by the overestimated direct SNP5 effect, arising from measurement error in SBP as noted before.

In summary, our simulations show that by accounting for measurement errors in the longitudinal QT risk factors and for dependencies between/within the traits, the proposed joint model improves estimation accuracy and correct classification of associations of SNPs directly associated with 
medRxiv preprint doi: https://doi.org/10.1101/2021.05.10.21256880; this version posted May 11, 2021. The copyright holder for this preprint (which was not certified by peer review) is the author/funder, who has granted medRxiv a license to display the preprint in perpetuity. It is made available under a CC-BY-NC 4.0 International license .

each time-to-event trait or indirectly associated via a measured longitudinal QT in comparison to classification using the CM-obs approach. However, when a SNP has both direct and indirect effects on a time-to-event trait, the proposed testing procedure can be conservative since it requires the joint significance of the two SNP effects, $\beta_{g(l)}$ and $\gamma_{g(k)}$, where the power of each test depends on effect size and the trait distribution. As a result, a SNP with a direct and an indirect association can be misclassified as either a direct or an indirect association. Finally, when a SNP has an indirect effect on both T1DC traits via an unmeasured QT, the testing procedure based on JM-mis, that captures some of the unexplained dependency between time-to-event traits through the frailty term, does not prevent misclassification as a direct association. This observation also shows the importance of the correct specification of the joint model - including all the intermediate QT(s) - to avoid misclassification of direct and/or indirect SNP associations.

\section{Application in the DCCT Genetics Study data}

We demonstrate the feasibility of the proposed approach by an application in the DCCT Genetics Study data. We use time to mild DR and time to persistent microalbuminuria, for DR and DN outcomes respectively, as previously defined in the motivating GWAS of $\mathrm{HbA} 1 \mathrm{c}^{19}$ (see Supplementary information SI-2 for details). Genome-wide genotyping in DCCT subjects was performed using HumanCoreExome Bead Array (Illumina, San Diego, CA, USA) and standard quality controls procedures were applied to individuals and genetic markers ${ }^{19,35}$. Ungenotyped autosomal SNPs were imputed using 1000 Genomes data phase $3^{36}$ (v5) and minimac3 ${ }^{37}$ (v.1.0.13), as previously described ${ }^{35}$.

Out of the 667 DCCT individuals, we analyze $N=516$ subjects with genetic data, without mild to moderate non-proliferative retinopathy or without DN event at DCCT baseline. By the time of the DCCT close-out visit, 297 (57.6\%) experienced a DR event, 61 (11.8\%) a DN event, including 47 subjects $(9.1 \%)$ that experienced both events. After SNP filtering and pruning on linkage disequilibrium (see Supplementary Information SI-2 for details), we analyze 307 candidate SNPs reported as associated with HbA1c, SBP, and multiple definitions of DR and/or DN $19,34,38-42$ (see Table S8 for the full list of SNPs).

Compared to the DCCT-based simulated datasets, the proportion of DN events observed in the application is lower. We expect that the test power for direct SNP association with DN under the joint model to be reduced; this implies reduce chances to correctly classify a SNP with either a direct or a direct and indirect association with DN. We also observe larger effects of HbA1c on T1DC traits $\left(\alpha_{1(k)}, k=1,2\right)$ and a smaller effect of SBP on DN $\left(\alpha_{2(2)}\right)$, as shown in Tables 2 vs S9. Larger $\alpha_{l(k)}$ values increase the contribution of the indirect effect $\left(\mu_{g(l, k)}\right)$ to the overall SNP effect $\left(\theta_{k(l)}\right)$, which can result in a direct SNP effect $\left(\gamma_{g(k)}\right)$ more severely biased if the longitudinal QT is not accounted properly in the joint model, while lower $\alpha_{l(k)}$ values reduce $\mu_{g(l, k)}$ and thus $\gamma_{g(k)}$ is less severely biased. Overall, in the DCCT application, we expect a SNP with an indirect effect via $\mathrm{HbA1c}$ on any T1DC trait to be more subject to be misclassified as having both a direct and indirect association, compared to the simulation results, while a SNP with an indirect effect via SBP on DN is less subject to this misclassification. 
medRxiv preprint doi: https://doi.org/10.1101/2021.05.10.21256880; this version posted May 11, 2021. The copyright holder for this preprint (which was not certified by peer review) is the author/funder, who has granted medRxiv a license to display the preprint in perpetuity. It is made available under a CC-BY-NC 4.0 International license.

Given prior evidence for cumulative effects of $\mathrm{HbA1c}$ on T1DC traits ${ }^{20,21}$, we compare joint model results obtained with contemporaneous, updated cumulative mean, and time-weighted cumulative $\mathrm{HbA} 1 \mathrm{c}$ effects on T1DC (Supplementary Information SI-2 for details). We present results under the latter association structure since it has a stronger prior association with T1DC and in the DCCT individuals analyzed here (Table S9). We obtain similar conclusions with alternative association structures (Figure S5-a). As shown in Figure 5-a, rs10810632 and rs1358030 are classified as indirect associations with both T1DC traits via their association with $\mathrm{HbA} 1 \mathrm{C}$ shared risk factor $\left(P_{\beta_{g(l)}} \leq P^{*}\right.$ and $P_{\gamma_{g(k)}}>P^{*}, P^{*}=1.7 \times 10^{-4}$ after Bonferroni correction for the 289.02 effective SNPs tested $\left.{ }^{43}\right)$. These two SNPs have calculated indirect effects $\left(\mu_{g(1, k)}\right)$ and $95 \%$ bootstrap confidence intervals that do not include 0 (Figure 5-b). As noted before, rs10810632 and rs1358030 were discovered previously in a GWAS of HbA1c in DCCT ${ }^{19}$. Classification of these two SNPs as direct and/or indirect associations may be affected by the Winner's curse bias, due to the modest sample size in this analysis, and the same individuals contributing to discovery and classification ${ }^{44,45}$. For the other candidate SNPs which were discovered in larger and/or independent studies ${ }^{19,34,38-42}$, we find little evidence of association with the discovery traits in marginal analyses (Table S8).

Conclusions regarding classification of direct and/or indirect associations based on the procedure using $P_{\gamma_{g(k)}}$ from CM-obs are similar to those based on the joint model results for all SNPs (Figure S5-b), although we noticed some differences in $P_{\gamma_{g(k)}}$; that could be explained by the attenuated association of $\mathrm{HbA} 1 \mathrm{c}$ and SBP with T1DC traits due to measurement errors ignored from CM-obs (Tables S10 vs S9).

\section{Discussion}

We present new methods for statistical genetic analysis under a joint model specification of multiple time-to-event traits and multiple longitudinal risk factors designed to characterize the complex genetic architecture of related traits in longitudinal studies of disease progression. The proposed model accounts for dependencies within and between traits and can account for traitspecific and shared covariates, measurement errors in the longitudinal traits, as well as effects of unobserved baseline confounding factors between the time-to-event traits through the subjectspecific frailty term.

Evaluation by realistic data-informed simulation study of complex T1DC genetic architecture shows that the proposed joint model improves estimation accuracy and efficiency compared to the Cox $\mathrm{PH}$ frailty model adjusted for observed longitudinal trait values as time-dependent covariates. This improvement holds particularly when the longitudinal risk factors are measured with errors or the time-to-event outcome has a low event rate. Indeed, measurement error attenuates the association of the longitudinal risk factor with the time-to-event trait, and as a result, if a SNP has an indirect effect induced by the QT, the estimated direct SNP effect on a time-toevent is biased away from zero. The magnitude of this bias tends to be worse with larger measurement error ${ }^{14,15}$. Identification of direct and/or indirect SNP associations is also facilitated under joint modelling in the presence of risk factor measurement error. When, however, a SNP has an indirect effect via an unmeasured longitudinal risk factor, both the proposed and $\mathrm{Cox} \mathrm{PH}$ 
medRxiv preprint doi: https://doi.org/10.1101/2021.05.10.21256880; this version posted May 11, 2021. The copyright holder for this preprint (which was not certified by peer review) is the author/funder, who has granted medRxiv a license to display the preprint in perpetuity. It is made available under a CC-BY-NC 4.0 International license .

model approaches produce biased estimates of the direct SNP effects. The extent of this bias depends on the magnitude of the effect sizes $\beta_{g(l)}$ and $\alpha_{l(k)}$. Although the frailty term in the joint model time-to-event sub-model captures some of the unexplained shared dependency between the time-to-event traits, we did not observe bias reduction of the direct SNP estimate in the case of an unmeasured risk factor, which can lead to misclassification of the SNP as a direct association. This may be a limitation of using a time-invariant frailty term that does not fully account for the indirect SNP effect via the unmeasured longitudinal risk factor. Because joint significance of both SNP effects is required to classify a SNP as having both direct and indirect associations, a SNP with both direct and an indirect association can be misclassified as having either a direct or an indirect association if one of the SNP effects is too small to be detected at the specified level. The proposed procedure can be adapted to other research questions, for example to identify SNPs that have direct association among the SNPs found associated with a longitudinal risk factor. In this case, it may be desirable to apply a less stringent significance threshold for the test of the direct SNP effect while controlling the overall type I error. Alternatively, intersection-union tests, as based on the likelihood ratio test ${ }^{46}$, could be used to assess joint significance of $\beta_{g(l)}$ and $\gamma_{g(k)}$ but would require computation of the full joint likelihood.

Application of the proposed joint model approach in longitudinal studies of disease progression, such as in the DCCT Genetics Study, improves classification of direct and/or indirect SNP association which can help to elucidate the genetic architecture of complex traits. In the context of mediation analysis, Liu et $\mathrm{al}^{47}$ discussed various formulations and interpretations of joint models, with shared-random-effects accounting for potential unmeasured baseline confounding factors between one longitudinal and one time-to-event traits. Using applications in datasets from two clinical trials, they illustrate interpretation of sensitivity analysis to unmeasured baseline confounders. Adaptation of the joint model we propose for multiple longitudinal and multiple timeto-event traits for mediation analysis requires extension of the mediation assumptions ${ }^{48,49}$ to the case of multiple mediators and multiple time-to-event traits. Specific evaluations of the proposed model under these assumptions are also warranted.

Although our primary aim in this report is to develop statistical methods to accurately distinguish among direct and/or indirect SNP associations with each time-to-event trait, the multi-trait aspect of the joint model lends itself to development of multi-trait SNP association testing for SNP discovery. In Supplementary Information SI-3, we present a joint-parameter test based on a generalized Wald statistic. In application to the simulated DCCT-based complex genetic architecture, we observe good type I error control under the global genetic null scenario, improved power for SNP discovery when a SNP has multiple trait effects, and power maintenance in other SNP association scenarios.

We acknowledge several features of the proposed joint model approach that warrant examination in further work. Firstly, to reduce computational complexity and improve model flexibility, we used two-stage parameter estimation. In some circumstances, this approach can produce biased estimates and/or underestimated standard errors ${ }^{16}$. Biased estimates can result from non-random censoring of the longitudinal trait values due to the occurrence of an event or from informative dropout ${ }^{50,51}$. Our simulation results show minimal biases in the absence of informative censoring, 
medRxiv preprint doi: https://doi.org/10.1101/2021.05.10.21256880; this version posted May 11, 2021. The copyright holder for this preprint (which was not certified by peer review) is the author/funder, who has granted medRxiv a license to display the preprint in perpetuity. It is made available under a CC-BY-NC 4.0 International license.

even when the joint model is mis-specified. In the DCCT application, characterized by administrative censoring and a high completion rate, these biases are of minimal concern because longitudinal trait values continued to be recorded regardless of the occurrence of any T1DC events; we estimated the trajectories using all the available measurements. Furthermore, we obtain robust bootstrap estimates of the covariance matrix, and simulation results under the null did not show deviation from expected distributions. Use of the bootstrap also facilitates joint testing of parameters from both stages. In the presence of informative censoring, we recommend sensitivity analysis using existing implementations joint likelihood estimation. To our knowledge those implementations only exist for simpler joint model formulation with either one longitudinal and one time-to-event trait ${ }^{52}$ or multiple longitudinal traits and one time-to-event outcome ${ }^{28,53}$. Secondly, because the joint model integrates longitudinal and time-to-event sub-models, model misspecification can occur in multiple ways and lead to invalid inference ${ }^{54}$. Therefore, we recommend a careful assessment of the model assumptions using joint model diagnostic tools ${ }^{23}$. Thirdly, patient visits were scheduled with high frequency in DCCT, so we ignored the modest degree of interval censoring in the current implementation of the joint model; when there are longer gaps between visits, extended methods are needed to account for interval censoring with additional simulation studies to assess impact on joint model estimates. Lastly, joint models are very computational demanding, particularly for genetic association studies that test millions of variants. In DCCT application, it took $\sim 60$ seconds to fit the joint model for each SNP and $\sim 1090.32$ more seconds ( 18 minutes) to estimate the covariance matrix with 500 bootstraps run in parallel on 4 nodes (each node with $40 \mathrm{CPU}$ and $202 \mathrm{~GB}$ RAM). While analysis at the genome level involving, up to 85 million 1000G-imputed SNPs in DCCT, seems computationally unrealistic, a screening approach without bootstrap to select the SNPs based on their association $P$-values, followed by the bootstrap refinement would reduce the computational burden. Recent computationally efficient algorithms have been developed to improve the efficiency of the linear mixed mode $\left.\right|^{55}$ and $\mathrm{Cox} \mathrm{PH}$ mode ${ }^{56,57}$ for genetic association studies, but to date, they remain to be implemented for multivariate outcomes.

With the increasing development of national biobanks ${ }^{58-60}$ consisting of a large collection of phenotypes, environmental factors, biomarkers and other risk factors collected over time and linked with genetic data, we anticipate that joint model methods can be applied to characterize the genetic architecture of complex traits using these data resources ${ }^{61}$. In addition, the results of such analysis could contribute towards the translation of human genetic findings to personalized medicine by providing more efficient SNP effect estimates for increased precision in polygenic risk score development ${ }^{62}$, and causal inference using mediation and mendelian randomization studies. Lastly, the joint model framework can also enable dynamic prediction beneficial for dynamic risk assessment ${ }^{7,63}$ and optimization of intervention strategies ${ }^{64,65}$. 
medRxiv preprint doi: https://doi.org/10.1101/2021.05.10.21256880; this version posted May 11, 2021. The copyright holder for this preprint (which was not certified by peer review) is the author/funder, who has granted medRxiv a license to display the preprint in perpetuity. It is made available under a CC-BY-NC 4.0 International license .

\section{Acknowledgements}

558

\section{Contributions}

585 GWAS: genome-wide association study;

586 HbA1c: Hemoglobin A1c;

587 LD: linkage disequilibrium;

588 MAF: minor allele frequency;

589 PH: proportional hazards; 
medRxiv preprint doi: https://doi.org/10.1101/2021.05.10.21256880; this version posted May 11, 2021. The copyright holder for this preprint (which was not certified by peer review) is the author/funder, who has granted medRxiv a license to display the preprint in perpetuity. It is made available under a CC-BY-NC 4.0 International license .

QT(s): quantitative trait(s);

591 SBP: systolic blood pressure;

592 SNP: single nucleotide polymorphism;

593 T1DC: type 1 diabetes complications.

\section{References}

595 1. Ibrahim, J.G., Chu, H., and Chen, L.M. (2010). Basic concepts and methods for joint models of 596 longitudinal and survival data. J. Clin. Oncol. 28, 2796-2801.

597 2. Chen, L.M., Ibrahim, J.G., and Chu, H. (2011). Sample size and power determination in joint 598 modeling of longitudinal and survival data. Stat. Med. 30, 2295-2309.

599 3. Hogan, J.W., and Laird, N.M. (1998). Increasing efficiency from censored survival data by using random effects to model longitudinal covariates. Stat. Methods Med. Res. 7, 28-48.

601 4. Wu, L., Liu, W., Yi, G.Y., and Huang, Y. (2012). Analysis of longitudinal and survival data: joint 602 modeling, inference methods, and issues. J. Probab. Stat. 2012, 1-17.

603 5. Asar, Ö., Ritchie, J., Kalra, P.A., and Diggle, P.J. (2015). Joint modelling of repeated 604 measurement and time-to-event data: An introductory tutorial. Int. J. Epidemiol. 44, 334-344.

605 6. Hickey, G.L., Philipson, P., Jorgensen, A., and Kolamunnage-Dona, R. (2016). Joint modelling of time-to-event and multivariate longitudinal outcomes: recent developments and issues. BMC Med. Res. Methodol. 16, 117. modeling of time-to-event and longitudinal outcomes. Annu. Rev. Stat. Its Appl. 6, 223-240.

610 8. Hickey, G.L., Philipson, P., Jorgensen, A., and Kolamunnage-Dona, R. (2018). Joint models of longitudinal and time-to-event data with more than one event time outcome: a review. Int. J.

612 Biostat. 14,.

613 9. Zhu, H., Ibrahim, J.G., Chi, Y.Y., and Tang, N. (2012). Bayesian influence measures for joint 614 models for longitudinal and survival data. Biometrics 68, 954-964.

615 10. Tang, N.S., Tang, A.M., and Pan, D.D. (2014). Semiparametric Bayesian joint models of 616 multivariate longitudinal and survival data. Comput. Stat. Data Anal. 77, 113-129.

617 11. Tang, A.M., and Tang, N.S. (2014). Semiparametric Bayesian inference on skew-normal joint 618 modeling of multivariate longitudinal and survival data. Stat. Med. 34, 824-843.

619 12. Bycott, P., and Taylor, J. (1998). A comparison of smoothing techniques for CD4 data 620 measured with error in a time-dependent Cox proportional hazards model. Stat. Med. 17, 20616212077.

622 13. Self, S., and Pawitan, Y. (1992). Modeling a marker of disease progression and onset of 
medRxiv preprint doi: https://doi.org/10.1101/2021.05.10.21256880; this version posted May 11, 2021. The copyright holder for this preprint (which was not certified by peer review) is the author/funder, who has granted medRxiv a license to display the preprint in perpetuity. It is made available under a CC-BY-NC 4.0 International license .

623

624

625

626

627

628

629

630

631

632

633

634

635

636

637

638

639

640

641

642

643

644

645

646

647

648

649

650

651

652

653

654

655

656

657

658

disease. In AIDS Epidemiology, (Boston, MA: Birkhäuser Boston), pp. 231-255.

14. Tsiatis, A.A., Degruttola, V., and Wulfsohn, M.S. (1995). Modeling the relationship of survival to longitudinal data measured with error. Applications to survival and CD4 counts in patients with AIDS. J. Am. Stat. Assoc. 90, 27-37.

15. Dafni, U.G., and Tsiatis, A.A. (1998). Evaluating Surrogate Markers of Clinical Outcome When Measured with Error. Biometrics 54, 1445.

16. Wulfsohn, M.S., and Tsiatis, A.A. (2006). A joint model for survival and longitudinal data measured with error. Biometrics 53, 330.

17. Paterson, A.D., and Bull, S.B. (2012). Does familial clustering of risk factors for long-term diabetic complications leave any place for genes that act independently? J. Cardiovasc. Transl. Res. 5, 388-398.

18. The Diabetes Control and Complications Trial Research Group (1993). The effect of intensive treatment of diabetes on the development and progression of long-term complications in insulindependent diabetes mellitus. N. Engl. J. Med. 329, 977-986.

19. Paterson, A.D., Waggott, D., Boright, A.P., Hosseini, S.M., Shen, E., Sylvestre, M.P., Wong, I., Bharaj, B., Cleary, P.A., Lachin, J.M., et al. (2010). A genome-wide association study identifies a novel major locus for glycemic control in type 1 diabetes, as measured by both $\mathrm{A} 1 \mathrm{C}$ and glucose. Diabetes 59, 539-549.

20. Lind, M., Odén, A., Fahlén, M., and Eliasson, B. (1995). The relationship of glycemic exposure $(\mathrm{HbA}(1 \mathrm{c}))$ to the risk of development and progression of retinopathy in the diabetes control and complications trial. Diabetes 53, 1093-1098.

21. Lind, M., Odén, A., Fahlén, M., and Eliasson, B. (2010). The shape of the metabolic memory of $\mathrm{HbA1c}$ : Re-analysing the DCCT with respect to time-dependent effects. Diabetologia 53, 10931098.

22. Laird, N.M., and Ware, J.H. (1982). Random-effects models for longitudinal data. Biometrics 38, 963-974.

23. Rizopoulos, D. (2012). Joint models for longitudinal and time-to-event data, with applications in $\mathrm{R}$ (Chapman and Hall/CRC).

24. Hougaard, P. (1995). Frailty models for survival data. Lifetime Data Anal. 1, 255-273.

25. Mauff, K., Steyerberg, E.W., Nijpels, G., van der Heijden, A.A.W.A., and Rizopoulos, D. (2017). Extension of the association structure in joint models to include weighted cumulative effects. Stat. Med. 36, 3746-3759.

26. Tsiatis, A.A., and Davidian, M. (2001). A semiparametric estimator for the proportional hazards model with longitudinal covariates measured with error. Biometrika 88, 447-458.

27. Tsiatis, A.A., and Davidian, M. (2004). Joint modeling of longitudinal and time-to-event data: An overview. Stat. Sin. 14, 809-834. 
medRxiv preprint doi: https://doi.org/10.1101/2021.05.10.21256880; this version posted May 11, 2021. The copyright holder for this preprint (which was not certified by peer review) is the author/funder, who has granted medRxiv a license to display the preprint in perpetuity. It is made available under a CC-BY-NC 4.0 International license .

659

660

661

662

663

664

665

666

667

668

669

670

671

672

673

674

675

676

677

678

679

680

681

682

683

684

685

686

687

688

689

690

691

692

693

694

695

696

697

28. Hickey, G.L., Philipson, P., Jorgensen, A., and Kolamunnage-Dona, R. (2018). JoineRML: A joint model and software package for time-to-event and multivariate longitudinal outcomes. BMC Med. Res. Methodol. 18,.

29. Therneau, T.M. (2020). A Package for survival analysis in R. R package version 3.2-7, URL http://CRAN.R-project.org/package=survival.

30. Terry M. Therneau, and Patricia M. Grambsch (2000). Modeling survival data: Extending the Cox model (New York: Springer).

31. Efron, B. (1981). Nonparametric estimates of standard error: The jackknife, the bootstrap and other methods. Biometrika 68, 589.

32. Steffes, M., Cleary, P., Goldstein, D., Little, R., Wiedmeyer, H.-M.M., Rohlfing, C., England, J., Bucksa, J., and Nowicki, M. (2005). Hemoglobin A1c measurements over nearly two decades: sustaining comparable values throughout the Diabetes Control and Complications Trial and the Epidemiology of Diabetes Interventions and Complications study. Clin. Chem. 51, 753-758.

33. Lorenzi, G.M., Braffett, B.H., Arends, V.L., Danis, R.P., Diminick, L., Klumpp, K.A., Morrison, A.D., Soliman, E.Z., Steffes, M.W., Cleary, P.A., et al. (2015). Quality control measures over 30 years in a multicenter clinical study: Results from the Diabetes Control and Complications Trial / Epidemiology of Diabetes Interventions and Complications (DCCT/EDIC) study. PLoS One 10, e0141286.

34. Hosseini, S.M., Boright, A.P., Sun, L., Canty, A.J., Bull, S.B., Klein, B.E.K., Klein, R., and Paterson, A.D. (2015). The association of previously reported polymorphisms for microvascular complications in a meta-analysis of diabetic retinopathy. Hum. Genet. 134, 247-257.

35. Roshandel, D., Gubitosi-Klug, R., Bull, S.B., Canty, A.J., Pezzolesi, M.G., King, G.L., Keenan, H.A., Snell-Bergeon, J.K., Maahs, D.M., Klein, R., et al. (2018). Meta-genome-wide association studies identify a locus on chromosome 1 and multiple variants in the MHC region for serum Cpeptide in type 1 diabetes. Diabetologia 61, 1098-1111.

36. 1000 Genomes Project Consortium, Auton, A., Brooks, L.D., Durbin, R.M., Garrison, E.P., Kang, H.M., Korbel, J.O., Marchini, J.L., McCarthy, S., McVean, G.A., et al. (2015). A global reference for human genetic variation. Nature 526, 68-74.

37. Das, S., Forer, L., Schönherr, S., Sidore, C., Locke, A.E., Kwong, A., Vrieze, S.I., Chew, E.Y., Levy, S., McGue, M., et al. (2016). Next-generation genotype imputation service and methods. Nat. Genet. 48, 1284-1287.

38. Wheeler, E., Leong, A., Liu, C.-T.T., Hivert, M.-F.F., Strawbridge, R.J., Podmore, C., Li, M., Yao, J., Sim, X., Hong, J., et al. (2017). Impact of common genetic determinants of Hemoglobin A1c on type 2 diabetes risk and diagnosis in ancestrally diverse populations: A transethnic genome-wide meta-analysis. PLoS Med. 14, e1002383.

39. Evangelou, E., Warren, H.R., Mosen-Ansorena, D., Mifsud, B., Pazoki, R., Gao, H., Ntritsos, G., Dimou, N., Cabrera, C.P., Karaman, I., et al. (2018). Genetic analysis of over 1 million people identifies 535 new loci associated with blood pressure traits. Nat. Genet. 50, 1412-1425.

40. Pollack, S., Igo, R.P., Jensen, R.A., Christiansen, M., Li, X., Cheng, C.-Y., Ng, M.C.Y., Smith, 
medRxiv preprint doi: https://doi.org/10.1101/2021.05.10.21256880; this version posted May 11, 2021. The copyright holder for this preprint (which was not certified by peer review) is the author/funder, who has granted medRxiv a license to display the preprint in perpetuity. It is made available under a CC-BY-NC 4.0 International license .

698

699

700

701

702

703

704

705

706

707

708

709

710

711

712

713

714

715

716

717

718

719

720

721

722

723

724

725

726

727

728

729

730

731

732

733

734

A. V, Rossin, E.J., Segrè, A. V, et al. (2019). Multiethnic genome-wide association study of diabetic retinopathy using liability threshold modeling of duration of diabetes and glycemic control. Diabetes 68, 441-456.

41. Grassi, M.A., Tikhomirov, A., Ramalingam, S., Below, J.E., Cox, N.J., and Nicolae, D.L. (2011). Genome-wide meta-analysis for severe diabetic retinopathy. Hum. Mol. Genet. 20, 24722481.

42. Sandholm, N., Salem, R.M., McKnight, A.J., Brennan, E.P., Forsblom, C., Isakova, T., McKay, G.J., Williams, W.W., Sadlier, D.M., Mäkinen, V.-P.P., et al. (2012). New susceptibility loci associated with kidney disease in type 1 diabetes. PLoS Genet. 8, e1002921.

43. Li, J., and Ji, L. (2005). Adjusting multiple testing in multilocus analyses using the eigenvalues of a correlation matrix. Heredity (Edinb). 95, 221-227.

44. Kraft, P. (2008). Curses-Winner's and Otherwise-in Genetic Epidemiology. Epidemiology 19, 649-651.

45. Sun, L., Dimitromanolakis, A., Faye, L.L., Paterson, A.D., Waggott, D., DCCT/EDIC Research Group, and Bull, S.B. (2011). BR-squared: a practical solution to the winner's curse in genomewide scans. Hum. Genet. 129, 545-552.

46. Schaid, D.J., Tong, X., Larrabee, B., Kennedy, R.B., Poland, G.A., and Sinnwell, J.P. (2016). Statistical methods for testing genetic pleiotropy. Genetics 204, 483-497.

47. Liu, L., Zheng, C., and Kang, J. (2018). Exploring causality mechanism in the joint analysis of longitudinal and survival data. Stat. Med. 37, 3733-3744.

48. Sobel, M.E. (1982). Asymptotic confidence intervals for indirect effects in structural equation models. Sociol. Methodol. 13, 290.

49. Mackinnon, D.P., Warsi, G., and Dwyer, J.H. (1995). A simulation study of mediated effect measures. Multivariate Behav. Res. 30, 41.

50. Albert, P.S., Shih, J.H., Albert, P.S., Shih, J.H., Albert1', P.S., and Shih2, J.H. (2010). On estimating the relationship between longitudinal measurements and time-to-event data using a simple two-stage procedure. Biometrics 66, 983-991.

51. Ye, W., Lin, X., and Taylor, J.M.G. (2008). Semiparametric modeling of longitudinal measurements and time-to-event data - A two-stage regression calibration approach. Biometrics $64,1238-1246$.

52. Rizopoulos, D. (2010). JM : An R Package for the joint modelling of longitudinal and time-toevent data. J. Stat. Softw. 35,.

53. Rizopoulos, D. (2016). The R package JMbayes for fitting joint models for longitudinal and time-to-event data using MCMC. J. Stat. Softw. 72,.

54. Arisido, M.W., Antolini, L., Bernasconi, D.P., Valsecchi, M.G., and Rebora, P. (2019). Joint model robustness compared with the time-varying covariate Cox model to evaluate the association between a longitudinal marker and a time-to-event endpoint. BMC Med. Res. 
medRxiv preprint doi: https://doi.org/10.1101/2021.05.10.21256880; this version posted May 11, 2021. The copyright holder for this preprint (which was not certified by peer review) is the author/funder, who has granted medRxiv a license to display the preprint in perpetuity. It is made available under a CC-BY-NC 4.0 International license .

Methodol. 19, 222.

55. Sikorska, K., Lesaffre, E., Groenen, P.J.F., Rivadeneira, F., and Eilers, P.H.C. (2018). Genome-wide analysis of large-scale longitudinal outcomes using penalization - GALLOP algorithm. Sci. Rep. 8,.

56. Rizvi, A.A., Karaesmen, E., Morgan, M., Preus, L., Wang, J., Sovic, M., Hahn, T., and Sucheston-Campbell, L.E. (2019). gwasurvivr: an R package for genome-wide survival analysis. Bioinformatics 35, 1968-1970.

57. Bi, W., Fritsche, L.G., Mukherjee, B., Kim, S., and Lee, S. (2020). A fast and accurate method for genome-wide time-to-event data analysis and its application to UK Biobank. J. Clean. Prod. 107, 222-233.

58. Bycroft, C., Freeman, C., Petkova, D., Band, G., Elliott, L.T., Sharp, K., Motyer, A., Vukcevic, D., Delaneau, O., O'Connell, J., et al. (2018). The UK Biobank resource with deep phenotyping and genomic data. Nature 562, 203-209.

59. Scholtens, S., Smidt, N., Swertz, M.A., Bakker, S.J.L., Dotinga, A., Vonk, J.M., Van Dijk, F., Van Zon, S.K.R., Wijmenga, C., Wolffenbuttel, B.H.R., et al. (2015). Cohort Profile: LifeLines, a three-generation cohort study and biobank. Int. J. Epidemiol. 44, 1172-1180.

60. Dummer, T.J.B., Awadalla, P., Boileau, C., Craig, C., Fortier, I., Goel, V., Hicks, J.M.T., Jacquemont, S., Knoppers, B.M., Le, N., et al. (2018). The Canadian Partnership for Tomorrow Project: A pan-Canadian platform for research on chronic disease prevention. Cmaj 190, E710E717.

61. Gasparini, A., Abrams, K.R., Barrett, J.K., Major, R.W., Sweeting, M.J., Brunskill, N.J., and Crowther, M.J. (2020). Mixed-effects models for health care longitudinal data with an informative visiting process: A Monte Carlo simulation study. Stat. Neerl. 74, 5-23.

62. Young, A.I., Benonisdottir, S., Przeworski, M., and Kong, A. (2019). Deconstructing the

63. Bull, L., Lunt, M., Martin, G., Hyrich, K., and Sergeant, J. (2020). Harnessing repeated measurements of predictor variables for clinical risk prediction: a review of existing methods. Diagnostic Progn. Res. 4, 1-16.

64. Sweeting, M.J., and Thompson, S.G. (2011). Joint modelling of longitudinal and time-to-event data with application to predicting abdominal aortic aneurysm growth and rupture. Biometrical $\mathrm{J}$. 53, 750-763.

65. Yuen, H.P., Mackinnon, A., Hartmann, J., Amminger, G.P., Markulev, C., Lavoie, S., Schäfer, M.R., Polari, A., Mossaheb, N., Schlögelhofer, M., et al. (2018). Dynamic prediction of transition to psychosis using joint modelling. Schizophr. Res. 202, 333-340.

66. Ibrahim, J.G., Chen, M.-H., and Sinha, D. (2001). Joint models for longitudinal and survival data. In EMR-IBS Bi-Annual Meeting, pp. 262-289. 
medRxiv preprint doi: https://doi.org/10.1101/2021.05.10.21256880; this version posted May 11, 2021. The copyright holder for this preprint (which was not certified by peer review) is the author/funder, who has granted medRxiv a license to display the preprint in perpetuity. It is made available under a CC-BY-NC 4.0 International license .

\section{Appendix}

773

774

775

776

777

778

779

780

781

782

783

784

785

786

787

788

789

790

791

792

793

794

795

796

797

798

799

800

Inference under the joint likelihood can be based on joint maximum-likelihood estimation, Bayesian estimation of the joint likelihood parameters, or a two-stage strategy ${ }^{23}$. Joint maximumlikelihood and Bayesian methods enable joint parameter estimation but can be computationally challenging, especially for multiple traits. Two-stage approaches ${ }^{12-15}$ sequentially fit the longitudinal (Stage 1) and time-to-event (Stage 2) sub-models, with trajectory estimates from Stage 1 incorporated into Stage 2; this can be relatively computationally efficient and lends itself to flexible model formulation. However, as noted in introduction, inference can be mis-calibrated because of propagation of errors ${ }^{16}$.

Joint likelihood function

Let $\Omega$ be the full parameter vector containing all fixed parameters from the longitudinal and timeto-event sub-models respectively. We assume:

$$
\text { (A1) } b_{i} \sim \operatorname{MVN}(0, D)
$$

(A2) $\varepsilon_{i j(l)} \sim N\left(0, \sigma_{(l)}^{2}\right)$ and $\varepsilon_{i j(l)} \perp \varepsilon_{i p(l)}$ between visits $j \neq p$

(A3) $b_{i(l)} \perp \varepsilon_{i j(l)}$

(A4) $u_{i} \perp b_{i}$

Given (A1)-(A4), it is appropriate to assume that the random effects $b_{i}$ account for: the association between the $L$ longitudinal traits; the association between both the longitudinal and time-to-event outcomes $^{66}$; and the serial correlation between the repeated measurements in each longitudinal process $^{22}$; and that given (A4), the frailty term accounts for the residual dependency between the time-to-event traits ${ }^{24}$. Under these conditional independence assumptions, the joint likelihood function of the model parameters given the observed data is:

$L\left(\Omega \mid Y_{i}, T_{i}, \delta_{i}, S N P_{i}, H_{i}, V_{i}\right)=\prod_{i=1}^{N} \int f_{1}\left(Y_{i} \mid b_{i}, \Omega\right) \times f_{2}\left(T_{i}, \delta_{i} \mid b_{i}, u_{i}, \Omega\right) \times f_{3}\left(b_{i} \mid \Omega\right) \times f_{4}\left(u_{i} \mid \Omega\right) d u_{i} d b_{i}$

where:

- $\quad\left(T_{i}, \delta_{i}\right)=\left(\left(T_{i(1)}, \delta_{i(1)}\right)^{\prime}, \ldots,\left(T_{i(k)}, \delta_{i(k)}\right)^{\prime}, \ldots,\left(T_{i(K)}, \delta_{i(K)}\right)^{\prime}\right)^{\prime}$

- $Y_{i}=\left(Y_{i(1)}{ }^{\prime}, \ldots, Y_{i(l)}{ }^{\prime}, \ldots, Y_{i(L)}{ }^{\prime}\right)^{\prime}$

- $f_{1}\left(Y_{i} \mid b_{i}, \Omega\right)=\prod_{l=1}^{L}\left(\frac{1}{\sqrt{2 \pi \sigma_{(l)}^{2}}}\right)^{n_{i}} \exp \left[-\frac{1}{2 \sigma_{(l)}^{2}} \prod_{j=1}^{n_{i}}\left(Y_{i j(l)}\left(t_{i j}\right)-Y_{i j(l)}^{*}\left(t_{i j}\right)\right)^{2}\right]$

- $f_{2}\left(T_{i}, \delta_{i} \mid b_{i}, u_{i}, \Omega\right)=\prod_{k=1}^{K}\left[\lambda_{i(k)}\left(T_{i(k)} \mid b_{i}, u_{i}, \Omega\right)\right]^{\delta_{i k}} S_{i(k)}\left(T_{i(k)} \mid b_{i}, u_{i}, \Omega\right)$

- $S_{i(k)}\left(T_{i(k)} \mid b_{i}, u_{i}, \Omega\right)$ 


$$
=\exp \left[-\int_{0}^{T_{i(k)}} \lambda_{i 0}(s) \exp \left\{\gamma_{g(k)} S N P_{i}+W_{i(k)}(s)+\gamma_{v(k)} V_{i(k)}+u_{i}\right\} d s\right]
$$
- $f_{4}\left(u_{i} \mid \Omega\right)=\frac{u_{i}^{a-1} \exp \left(-u_{i} / b\right)}{\Gamma(a) b^{a}}$, i.e. we assume $u_{i} \sim \Gamma(a, b)$, with $a, b>0$.

Calculation of this full likelihood requires multivariate integration with respect to the random effect's distribution, which can lead to demanding computation. When the random effect vector $b_{i}$, has a small dimension, say less than 3 , the integral can be evaluated via Gaussian quadrature which approximates the integral by a weighted sum of the target function evaluated at prespecified sample points. However, when the dimension is larger, it is demanding to calculate the integrals with satisfactory approximation accuracy. Although a full likelihood specification enables rigorous study of asymptotic properties, its large sample approximation may not be accurate when sample size is small. In comparison, the Bayesian paradigm does not require asymptotic approximations, but the design of an efficient sampling algorithm to study the posterior distribution is challenging.

\section{Likelihood functions under the two-stage approximation}

815 Let $\Omega$ and $\Gamma$ be the vectors containing all fixed parameters from the longitudinal and time-to-event sub-models respectively.

Stage 1: Multivariate mixed model

$$
L\left(\Omega \mid Y_{i}, X_{i}, C_{i}\right)=\prod_{i=1}^{N} \int_{b_{i}} f_{1}\left(Y_{i} \mid b_{i}, \Omega\right) \times f_{3}\left(b_{i} \mid \Omega\right) d b_{i}
$$

$$
L\left(\Gamma \mid T_{i}, \delta_{i}, C_{i}\right)=\prod_{i=1}^{N} \int_{u_{i}} f_{2}\left(T_{i}, \delta_{i} \mid \widehat{Y_{l(l)}^{*}}\left(T_{i}\right), u_{i}, \Gamma\right) \times f_{4}\left(u_{i} \mid \Gamma\right) \times d u_{i}
$$

Where:

$$
\left.\left.u_{i}\right\} d s\right]
$$

- With $W_{i(k)}(s)=\sum_{l=1}^{L_{k}} \alpha_{l(k)} f_{l(k)}\left(\widehat{Y_{l(l)}^{*}}(\mathrm{~s})\right)$ 
medRxiv preprint doi: https://doi.org/10.1101/2021.05.10.21256880; this version posted May 11, 2021. The copyright holder for this preprint (which was not certified by peer review) is the author/funder, who has granted medRxiv a license to display the preprint in perpetuity. It is made available under a CC-BY-NC 4.0 International license.

826 Unlike the joint likelihood function, where the shared random effects $b_{i}$ account for the 827 dependencies between the longitudinal and the time-to-event traits, the two-stage approach 828 accounts for the dependencies between the longitudinal and time-to-event traits via the fitted 829 values of the longitudinal trajectories. As mentioned previously, this approximation can produce 830 biased estimates and/or underestimated standard errors ${ }^{16}$, particularly in presence of non-random 831 censoring of the longitudinal trait values due to the occurrence of an event or from informative 832 dropout ${ }^{50,51}$ and/or because of propagation errors of Stage 1 parameters in Stage $2^{16}$. Indeed, 833 informative missingness/dropouts lead in differential follow-up between patients with and without 834 an event, the time-to-event processes are related to the length of the follow-up, and thus the 835 random effects $b_{i(l)}$ can depend on the event times (e.g. patients who have an event early are 836 more likely to have positive random slopes). However, in absence of informative 837 dropouts/missingness, as we showed in our simulation studies, this approach has low bias and is 838 computationally feasible for genetic association studies. 
Multivariate mixed-effects sub-model for $L$ longitudinal QT(s) (and/or risk factors)

Measured longitudinal traits:

$$
Y_{i(l)}\left(t_{i j}\right)=Y_{i(l)}^{*}\left(t_{i j}\right)+\varepsilon_{i j(l)} \sim N\left(0, \sigma_{(l)}^{2}\right)
$$

- intermittently (ie scheduled visits)

- measurement errors (ie biological variation)

- potentially informatively missing values

\section{Longitudinal trajectories:}

$Y_{i(l)}^{*}\left(t_{i j}\right)=\beta_{0(l)}+b_{i 0(l)}+\left(\beta_{1(l)}+b_{i 1(l)}\right) t_{i j}+\beta_{g(l)} S N P_{i}+\beta_{h(l)} H_{i(l)}$

- latent and continuous processes

- various shapes (linear/non-linear)

- smoothed, account for measurement errors

- account for shared and/or trait-specific covariates

- $b_{i} \sim N_{2 L}(0, D)$ : subject-specific deviation from average trajectories

- $D$ : dependencies within/between $L$ traits

Time-dependent association structures

$$
W_{i(k)}(t)=\sum_{l=1}^{L_{k}} \alpha_{l(k)} f_{l(k)}\left(Y_{i(l)}^{*}(t)\right)
$$

- account for the indirect SNP effects induced by each QT I

- $\alpha_{l(k)}$ association between each pair of traits I\&k

- $f_{l(k)}\left(Y_{i(l)}^{*}(t)\right)$, functional dependence between traits I \& $k$, based on prior knowledge

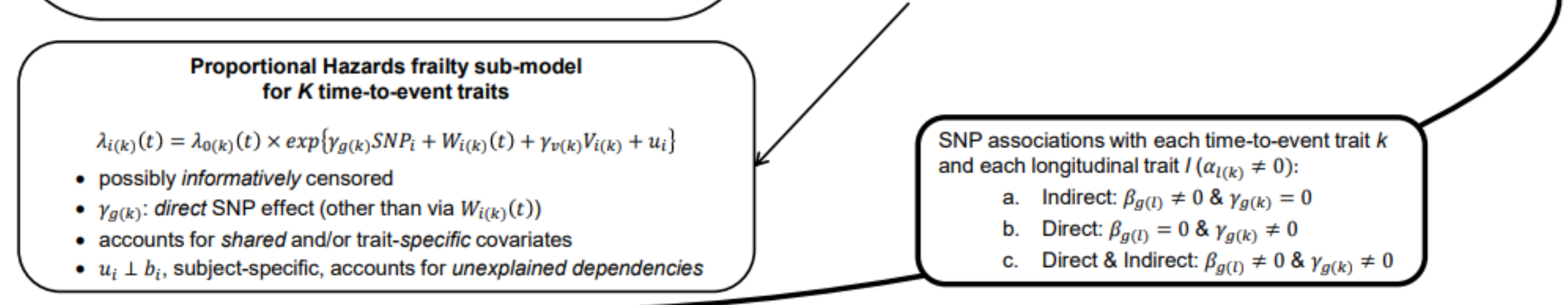

Fiqure 1. Proposed joint modelling approach for characterization of complex genetic architecture of multiple disease progression 


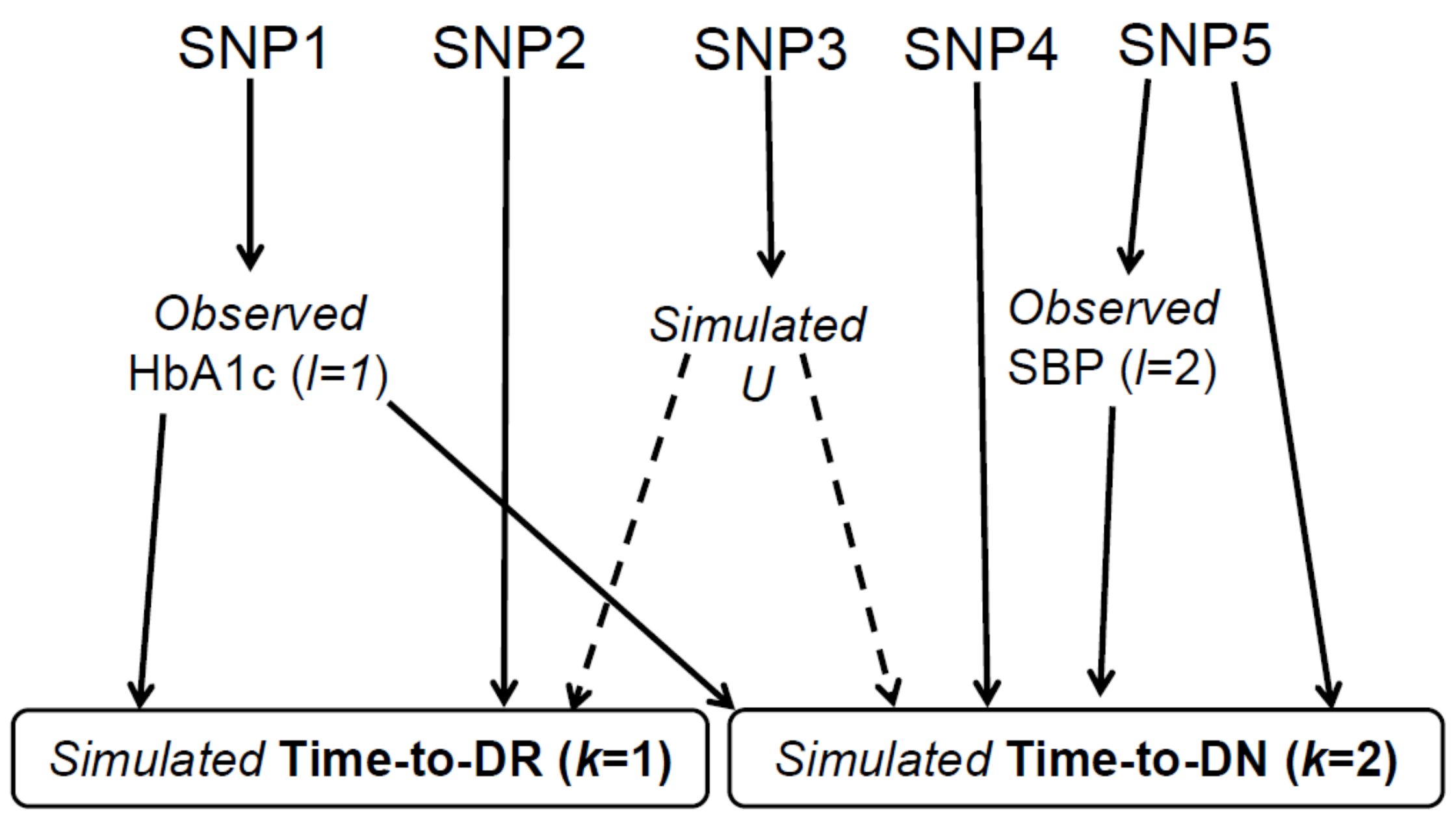

Figure 2. Realistic DCCT-data-based causal genetic scenario

The effect of gender on SBP (noted as $H_{i(2)}$ ), and effects of T1D duration at baseline (noted as $V_{i(k)}$ ) on both time-to-T1DC ( $k=1$, 2) traits are not represented in this figure, but are included in the data generating model, see Supplementary Information SI-1 for details. We simulated $R=1000$ replicates of $N=667$ DCCT individuals with $M=5$ causal variants and $K=2$ time-to-event traits simulated under this causal genetic scenario and $R=1000$ replicates of $M=5$ SNPs (with same MAF as the causal ones) under a global null genetic scenario where none of the SNPs is associated with any traits. 


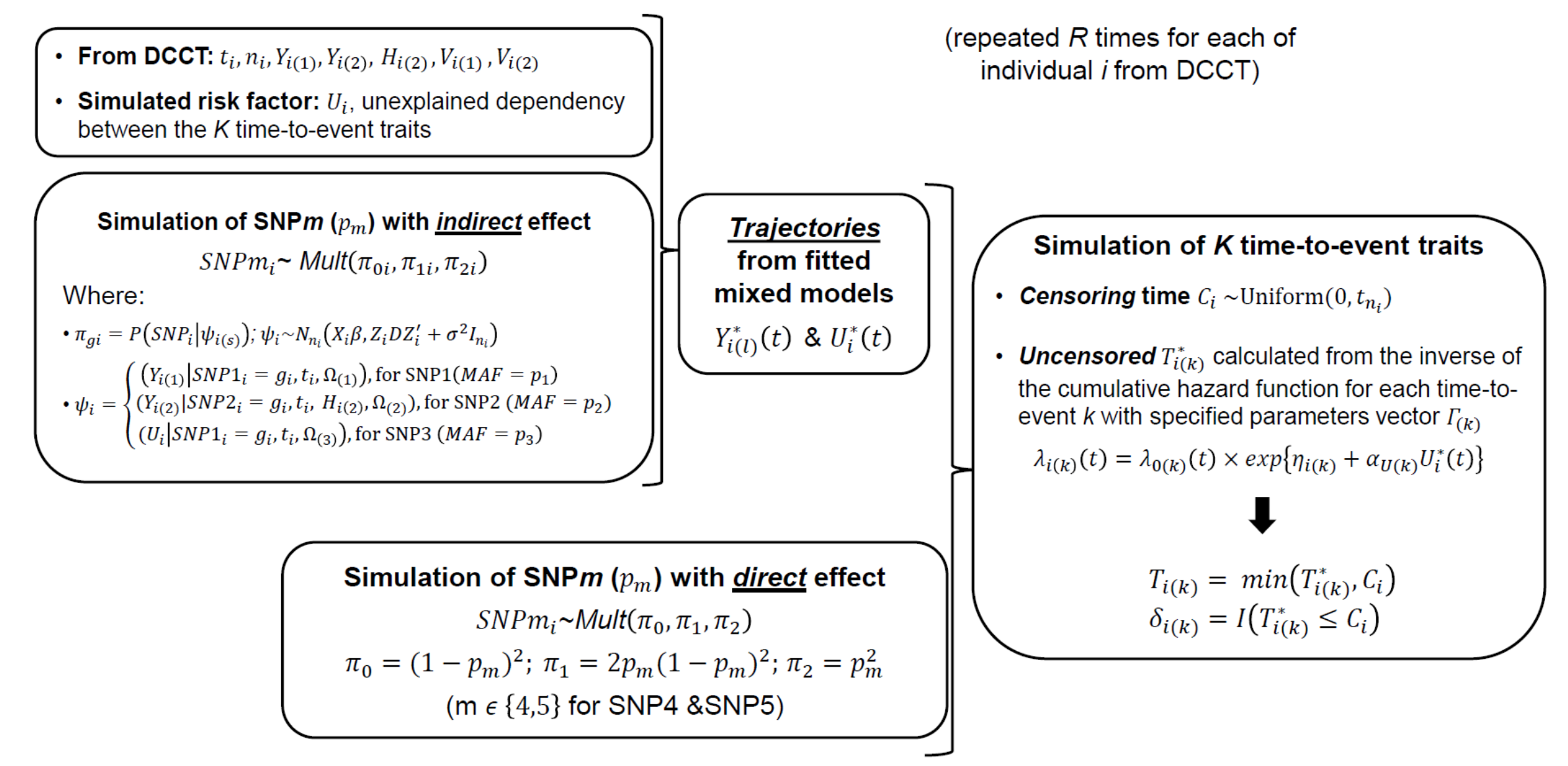

\section{Figure 3. Illustration of the procedure developed for DCCT-based simulation study under the scenario from Figure 2}

$\Omega_{(1)}, \Omega_{(2)}$ and $\Omega_{(U)}$ are specified parameter values for the longitudinal trait models, and $\Gamma_{(1)}, \Gamma_{(2)}$ for the time-to-event trait models, $p$ is the specified vector of minor allele frequencies vector of the MSNPs. Parameters for the causal genetic scenario in Figure 2 are summarized in Table 2 and in Table S1. The DCCT-data-based simulation algorithm uses longitudinal trait/baseline covariates from DCCT and simulated genetic data and time-toevent traits. SNPs with indirect effects are simulated from a multinomial distribution with conditional genotype probabilities $\left(\pi_{0 i}, \pi_{1 i}, \pi_{2 i}\right)$ using longitudinal trait values for individual $i$. Here, $X_{i}$ and $Z_{i}$ denote the design matrices of the fixed and random effects of the mixed model assumed for each longitudinal trait and $D$ is the specified covariance matrix for the random effects. SNPs with direct effects are simulated from the population probabilities, that depend on the MAF. Each time-to-event trait $k$ is simulated by calculating the inverse of the cumulative specified hazard function using the Brent univariate root-finding method ${ }^{34,35}$. For DR, $\eta_{i(1)}=\gamma_{g(1)} S N P 2_{i}+\alpha_{1(1)} Y_{i(1)}^{*}(t)+\gamma_{v(1)} V_{i(1)}$ and for DN, $\eta_{i(2)}=\gamma_{g(2)} S N P 4_{i}+$ $\gamma_{g(2)}^{\prime} S N P 5_{i}+\sum_{l=1}^{2} \alpha_{l(1)} Y_{i(l)}^{*}(t)+\gamma_{v(2)} V_{i(2)}$. We further added the effect of the longitudinal trajectory $U_{i}^{*}(t)$ to each $\eta_{i(k)}$ in the hazard function of each trait $k$ to induce some unexplained dependencies between the simulated time-to-event traits. Details of the DCCT-based simulation procedure are presented in Supplementary Information SI-1. 

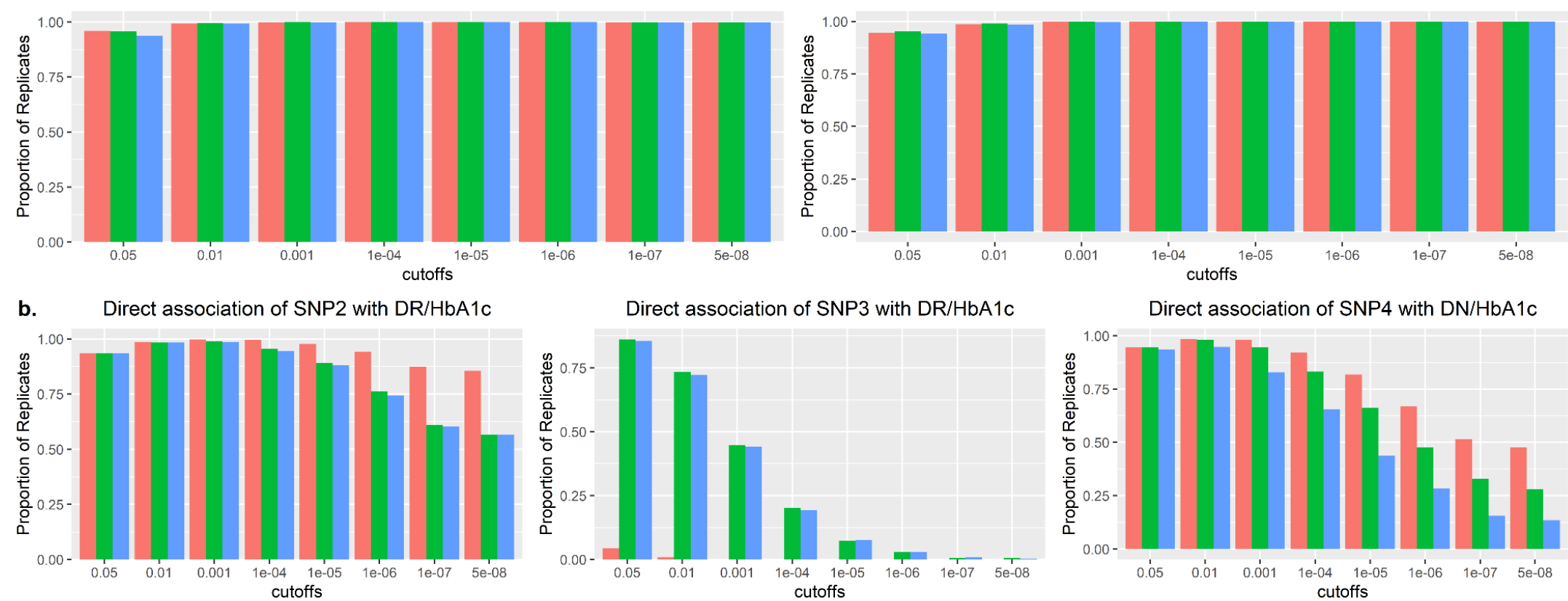

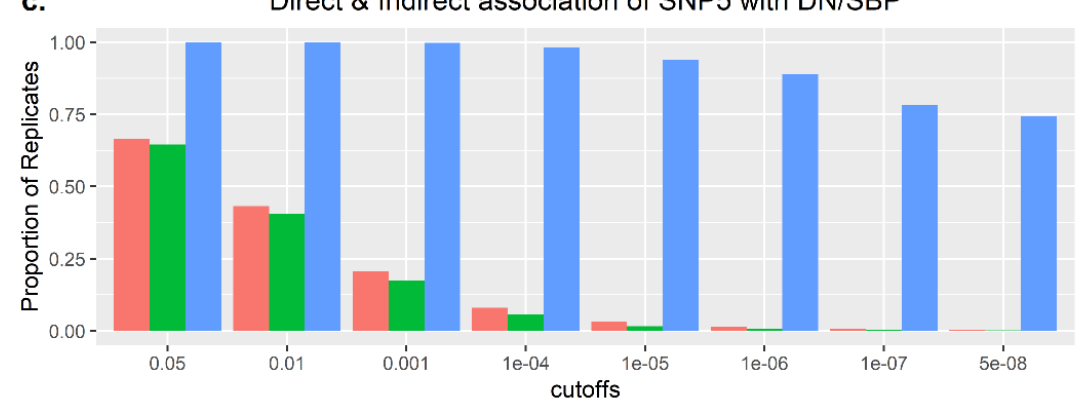

d.

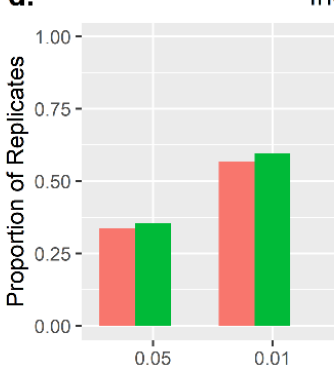

Indirect association of SNP5 with DN/SBP

Figure 4. Performance of the testing procedure to recover underlying generating causal relationships from Figure 2, assessed using $R=1000$ replicates of $N=667$ DCCT subjects.

The $Y$ axis represents the proportion of replicates that accurately classify each causal SNP as: (a.) indirect; (b.) direct and (c.) direct and indirect causal associations for SNP1, SNP2, SNP4 and SNP5. SNP3 is tested as a direct association because the longitudinal risk factor $U$ is assumed unmeasured. Results obtained for direct association of SNP3 and SNP4 with DN/SBP are similar to those presented for DN/HbA1c (Figure S4) and are not shown here. Plot (d.) shows that SNP5 is misclassified as an indirect association in a larger number of replicates compared to (c.) by the joint models compared to CM-obs. This misclassification rate tends to increase with decreasing $P^{*}$. Classification rates of all these SNPs with other timeto-event/longitudinal trait pairs are presented in Figure S4. 
medRxiv preprint doi: https://doi.org/10.1101/2021.05.10.21256880; this version posted May 11, 2021. The copyright holder for this preprint (which was not certified by peer review) is the author/funder, who has granted medRxiv a license to display the preprint in perpetuity. It is made available under a CC-BY-NC 4.0 International license .

a.
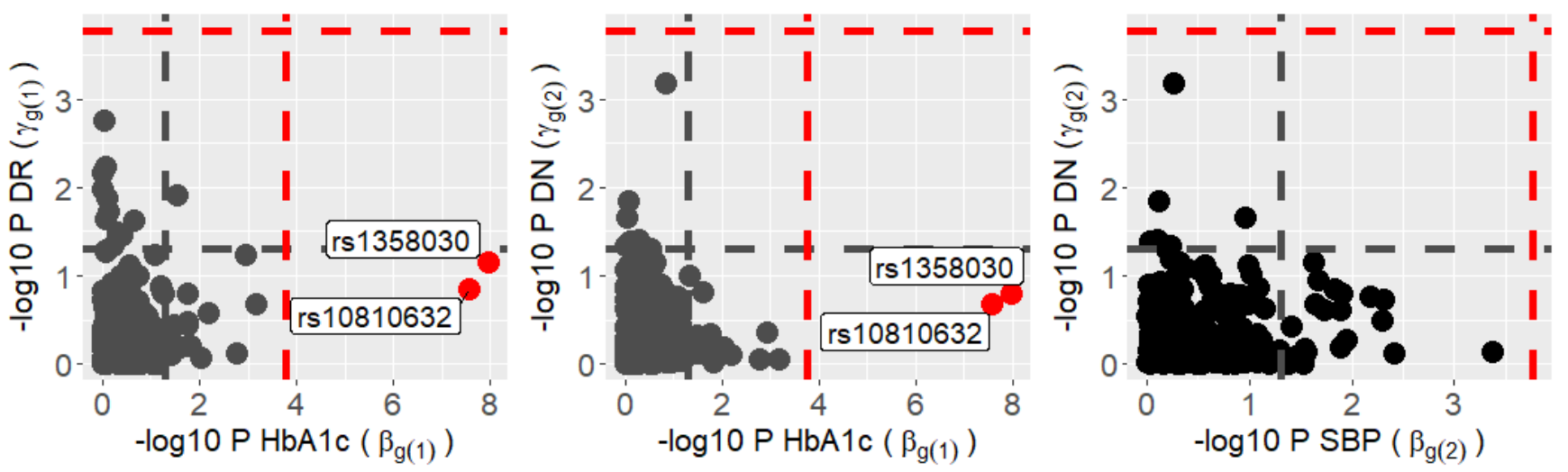

b.
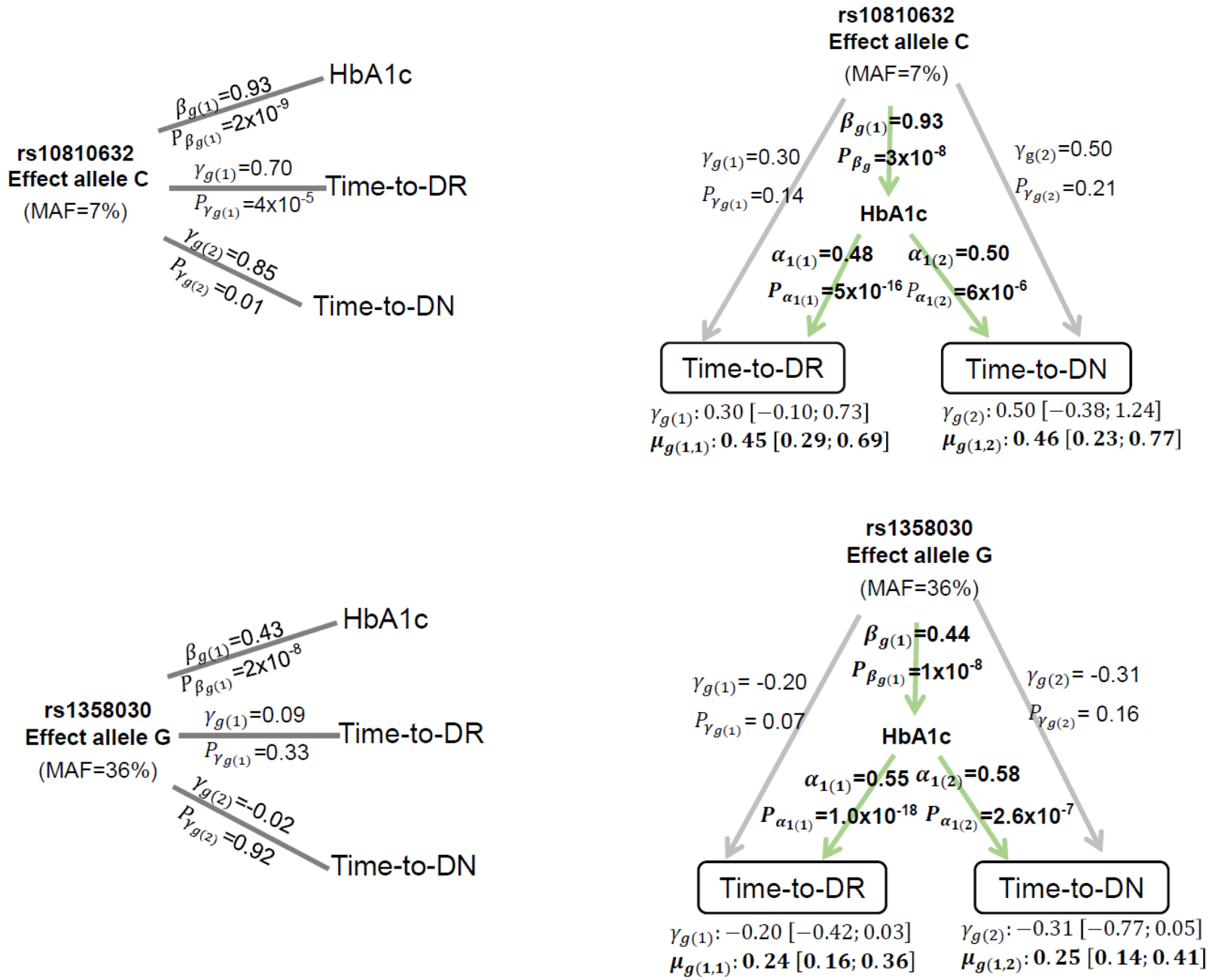

Figure 5. Classification of direct and/or indirect SNP associations in the DCCT Genetics Study data.

(a.) Scatter plots of the P-values (-log10) for tests of $\beta_{g(l)}\left(X\right.$ axis) and $\gamma_{g(k)}(Y$ axis) for DR/HbA1c, DN/HbA1c and DN/ SBP trait pairs. Significance levels $P^{*}=1.7 \times 10^{-4}$ and $P^{*}=0.05$ are indicated by red and grey horizontal and vertical dashed lines. (b.) Association results for the two SNPs that exibit indirect association with DR/DN outcomes at $P^{*}=1.7 \times 10^{-4}$. Left panel present results from separate analysis of each trait; and right panel presents results from the joint model with bootstrap 95\% confidence intervals for the direct and indirect SNP effects. Results are presented using the time-weighted cumulative HbA1c effects on T1DC traits. 


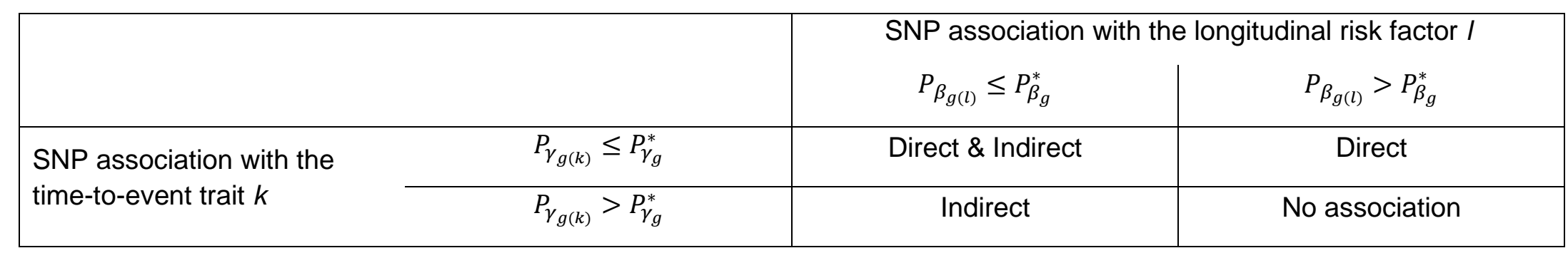

$P_{\beta_{g(l)}}$ and $P_{\gamma_{g(k)}}$ are the $P$-values from Wald test (1df) for SNP effects $\beta_{g(l)}$ and $\gamma_{g(k)}$.

$P_{\beta_{g}}^{*}$ and $P_{\gamma_{g}}^{*}$ are the significance thresholds (see methods for details). Note that thorough the paper, we use $P^{*}=P_{\beta_{g}}^{*}=P_{\gamma_{g}}^{*}$, but different levels can be specified for $P_{\beta_{g}}^{*}$ and $P_{\gamma_{g}}^{*}$.

Table 1. Hypothesis testing procedure to classify a SNP as having a direct and/or an indirect association with a time-to-event trait $k$ and an associated longitudinal risk factor $I$. 


\begin{tabular}{|c|c|c|c|c|c|c|c|}
\hline \multirow[b]{2}{*}{ Causal SNPs } & \multirow[b]{2}{*}{ Type of SNP association } & \multirow{2}{*}{$\begin{array}{l}\text { Specified } \\
\text { parameters }^{1}\end{array}$} & \multicolumn{5}{|c|}{ Empirical power (separate analysis of each trait) ${ }^{2}$} \\
\hline & & & $\begin{array}{l}\text { Trait (Tested } \\
\text { parameter) }\end{array}$ & $P^{*}=0.05$ & $P^{*}=0.001$ & $P^{*}=10^{-5}$ & $P^{*}=5 \times 10^{-8}$ \\
\hline \multirow{3}{*}{$\begin{array}{c}\text { SNP1 } \\
(\mathrm{MAF}=0.30)\end{array}$} & \multirow{3}{*}{$\begin{array}{l}\text { Indirect association with both } \\
\text { T1DC traits via } \mathrm{HbA1c}\end{array}$} & $\beta_{g(1)}=0.70$ & $\mathrm{HbA1c}\left(\beta_{g(1)}\right)$ & $100 \%$ & $100 \%$ & $100 \%$ & $99.8 \%$ \\
\hline & & \multirow{2}{*}{$\begin{array}{l}\alpha_{1(1)}=0.20 \\
\mu_{g(1, k)}=0.14\end{array}$} & $\mathrm{DR}\left(\gamma_{g(1)}\right)$ & $20.4 \%$ & $1.2 \%$ & $<10^{-4}$ & $<10^{-4}$ \\
\hline & & & $\mathrm{DN}\left(\gamma_{g(2)}\right)$ & $8.70 \%$ & $0.3 \%$ & $<10^{-4}$ & $<10^{-4}$ \\
\hline $\begin{array}{c}\text { SNP2 } \\
(\mathrm{MAF}=0.10) \\
\end{array}$ & Direct association with DR & $\gamma_{g(1)}=0.80$ & $\mathrm{DR}\left(\gamma_{g(1)}\right)$ & $100 \%$ & $98.3 \%$ & $87.4 \%$ & $58.2 \%$ \\
\hline \multirow{2}{*}{$\begin{array}{c}\text { SNP3 } \\
(\mathrm{MAF}=0.40)\end{array}$} & \multirow{2}{*}{$\begin{array}{l}\text { Indirect association with both } \\
\text { T1DC traits via } U\end{array}$} & \multirow{2}{*}{$\begin{array}{l}\beta_{g(U)}=0.80 \\
\alpha_{1(U)}=0.40 \\
\mu_{g(1, k)}=0.36\end{array}$} & $\operatorname{DR}\left(\gamma_{g(1)}\right)$ & $87.5 \%$ & $42.8 \%$ & $7.6 \%$ & $0.9 \%$ \\
\hline & & & $\mathrm{DN}\left(\gamma_{g(2)}\right)$ & $32.6 \%$ & $2.6 \%$ & $<10^{-3}$ & $<10^{-3}$ \\
\hline $\begin{array}{c}\text { SNP4 } \\
(\mathrm{MAF}=0.30)\end{array}$ & Direct association with DN & $\gamma_{g(2)}=0.70$ & $\mathrm{DN}\left(\gamma_{g(2)}\right)$ & $94.1 \%$ & $56.5 \%$ & $17.3 \%$ & $4.0 \%$ \\
\hline \multirow[b]{2}{*}{$\begin{array}{c}\text { SNP5 } \\
(\mathrm{MAF}=0.20)\end{array}$} & \multirow[b]{2}{*}{$\begin{array}{l}\text { Direct and indirect association } \\
\text { with DN via SBP }\end{array}$} & $\beta_{g(2)}=7.00$ & $\operatorname{SBP}\left(\beta_{g(2)}\right)$ & $100 \%$ & $100 \%$ & $100 \%$ & $100 \%$ \\
\hline & & $\begin{array}{l}\alpha_{2(2)}=0.20 \\
\mu_{g(2,2)}=1.40 \\
\gamma_{g(2)}=0.40\end{array}$ & $\mathrm{DN}\left(\gamma_{g(2)}\right)$ & $100 \%$ & $100 \%$ & $99.8 \%$ & $98.0 \%$ \\
\hline
\end{tabular}

${ }^{1} \beta_{g(l)}$ is the SNP effect on the longitudinal trait $l, \gamma_{g(k)}$ is the direct SNP effect on the time-to-event trait $k ; \alpha_{l(k)}$ is the effect of each longitudinal trajectory for trait $/$ on the time-to-event trait $k . \mu_{g(l, k)}$ is the indirect SNP effect, calculated as $\mu_{g(l, k)}=\beta_{g(l)} \alpha_{l(k)}$.

${ }^{2}$ For each scenario of direct/indirect SNP association, we present the empirical power to detect each SNP using separate analysis of each trait (linear mixed model for each longitudinal trait, Cox PH model for each time-to-event trait); as typically used for SNP discovery. Models are adjusted for all nonSNP baseline covariates, except $U$, as specified to simulate the data. The empirical power is calculated as the proportion of replicates in the causal scenario from Figure 2 with a significant SNP association detected at specified levels of $P^{*}$. As expected, SNP1, SNP3 and SNP5 appear associated with the T1DC outcomes due to their indirect effects induced by longitudinal risk factors absents from the time-to-event models. For comparisons, empirical power of the same tests based on parameters from the joint model are presented in Table S2.

Table 2. Simulated scenarios of direct and/or indirect SNP associations, assessed using $R=1000$ replicates of $N=667$ DCCT subjects simulated under the causal genetic scenario. This table presents parameters specified for SNPs and trajectory effects on time-to-event traits for the DCCT-based simulation study and illustrates how each type of SNP would be detected in GWAS discovery analysis based on separate analysis of each trait. 


\begin{tabular}{|c|c|c|c|c|c|c|c|}
\hline \multirow{2}{*}{ SNPs $^{1}$} & \multirow{2}{*}{ Trait pairs } & \multicolumn{3}{|l|}{$P^{*}=0.05$} & \multicolumn{3}{|l|}{$P^{*}=0.01$} \\
\hline & & JM-cmp & JM-mis & CM-obs & JM-cmp & JM-mis & CM-obs \\
\hline \multicolumn{8}{|c|}{ Indirect association } \\
\hline \multirow{2}{*}{ SNP1 } & $\mathrm{DR} / \mathrm{HbA1c}$ & 0.049 & 0.049 & 0.500 & 0.015 & 0.015 & 0.015 \\
\hline & $\mathrm{DN} / \mathrm{HbA1c}$ & 0.049 & 0.048 & 0.048 & 0.015 & 0.015 & 0.015 \\
\hline \multicolumn{8}{|c|}{ Direct association } \\
\hline SNP2 & $\mathrm{DR} / \mathrm{HbA1c}$ & 0.058 & 0.045 & 0.045 & 0.009 & 0.009 & 0.007 \\
\hline \multirow{3}{*}{ SNP3 } & $\mathrm{DR} / \mathrm{HbA} 1 \mathrm{c}$ & 0.041 & 0.044 & 0.041 & 0.008 & 0.006 & 0.008 \\
\hline & $\mathrm{DN} / \mathrm{HbA1c}$ & 0.041 & 0.037 & 0.042 & 0.012 & 0.008 & 0.008 \\
\hline & $\mathrm{DR} / \mathrm{HbA1c}$ & 0.042 & 0.034 & 0.036 & 0.012 & 0.008 & 0.009 \\
\hline \multirow{2}{*}{ SNP4 } & $\mathrm{DN} / \mathrm{HbA1c}$ & 0.046 & 0.044 & 0.048 & 0.007 & 0.009 & 0.005 \\
\hline & DN/SBP & 0.047 & 0.044 & 0.042 & 0.008 & 0.009 & 0.005 \\
\hline \multicolumn{8}{|c|}{ Direct and Indirect association } \\
\hline SNP5 & DN/SBP & $<0.001$ & 0.002 & 0.003 & $<0.001$ & $<0.001$ & $<0.001$ \\
\hline
\end{tabular}

${ }^{1}$ Each SNP is tested with the same direct/indirect association tests as applied to the causal SNPs, except SNP3 that is tested as a direct association because the longitudinal risk factor $U$ is assumed unmeasured. Classification rates for all other possible QT/time-to-event trait pairs are presented in Figure S3.

2 JM-cmp denotes the complete joint model fitted for each SNP separately, including all non-genetic covariates used for the data simulation (including $U$ ).

Table 3. Classification rates of the procedure for each SNP under the global null genetic scenario, assessed using $R=1000$ replicates of $N=667$ DCCT subjects. 